\title{
Atlantic surfclam connectivity within the Middle Atlantic Bight: Mechanisms underlying variation in larval transport and settlement.
}

\author{
Xinzhong Zhang1, Daphne Munroe ${ }^{2,}$, Dale Haidvogel $^{1}$, Eric N. Powell ${ }^{3}$
}

1. Institute of Marine and Coastal Science, Rutgers University, New Brunswick, NJ, USA

2. Haskin Shellfish Research Laboratory, Rutgers University, Port Norris, NJ, USA

3. Gulf Coast Research Laboratory, The University of Southern Mississippi, Ocean Springs, MS, USA

\section{Highlights:}

- An annually varying north to south connectivity exists for surfclam larvae.

- Highest settlement rates correspond to favorable average temperatures.

- Along-shore larval transport varies with along-shore surface wind stress.

- Seasonal variation in larval dispersal is driven by across-shelf density gradient.

- Thermally driven larval behavior explains differences in across-shelf dispersal.

\begin{abstract}
:
Larval transport and settlement have been shown in various studies to be essential in determining population abundance and connectivity for benthic invertebrates. This transport is influenced by both the physical environment and biological behavior. The Atlantic surfclam, Spisula solidissima, is a commercially important benthic invertebrate fishery species along the U.S northeastern coast. In this study, a physical circulation model is coupled to a surfclam larval model to investigate the dynamics of larval transport and settlement within the Middle Atlantic Bight (MAB) shelf in 2006. The main physical mechanisms causing variability in larval transport and settlement are also examined. Model results show that surfclam larvae released from July to early October experience
\end{abstract}

\footnotetext{
* Corresponding author.

Contact number: (856) 785-0074 ext. 4325.

E-mail address: dmunroe@hsrl.rutgers.edu (Daphne Munroe)
} 
relatively larger settlement rates, due to higher average temperatures experienced by larvae. Larval along-shore transport exhibits a mean down-coast pattern following the coastal current from the northeast to the southwest, with most high-frequency (period of $2 \sim 10$ days) variations caused by fluctuations in the along-shore surface wind stress, and with seasonal variations speculated to be driven mainly by changes in the across-shelf density gradient. Larval across-shelf movement is highly correlated with the along-shore surface wind stress mediated by coastal upwelling and downwelling episodes, but the correlation is further dependent on the vertical distribution of the larvae, particularly their position relative to the thermocline. Most surfclam larvae released from the Middle Atlantic shelf stay below the thermocline and experience a net onshore transport during the summer-stratified season when upwelling-favorable wind forcing dominates. A proposed critical value of water temperature at the thermocline successfully regulates the observed patterns of vertical distribution of surfclam larvae and their across-shelf movement off the New Jersey and South Virginia shelves; that is, when the water temperature at the thermocline is above the critical value $\left(19.0^{\circ} \mathrm{C}\right)$, surfclam larvae tend to escape the warm surface layer to concentrate below the thermocline and follow the across-shelf movement of bottom water, and vice versa. These results provide an important insight into the general mechanism of how physical environmental factors interact with biological behavior of the larvae to influence larval transport, connectivity and population dynamics, and also indicate the potential impact of large-scale climate change on benthic species and coastal ecosystems.

Key words: surfclam (Spisula solidissima), larval transport, larval settlement, larval behavior, Middle Atlantic Bight, upwelling/downwelling

\section{Introduction*}

\footnotetext{
${ }^{*}$ The primary abbreviations used in this article: MABGOM: Middle Atlantic Bight and Gulf of Maine physical circulation model; MAB - Middle Atlantic Bight; SVA - South Virginia; DMV - Delmarva; NJ - New Jersey; LI - Long Island; SNE South New England; GBK - Georges Bank; NEFSC - Northeast Fisheries Science Center of U.S. Abbreviations of NJ", DMV*, and SVA* were also used to be distinguished from NJ, DMV and SVA, to indicate the arbitrarily chosen shelves for the larval daily movement study (Fig. 2), whereas those without an asterisk (SVA, DMV, NJ, LI, SNE, GBK) correspond to the larval release regions inferred from the historical observations of surfclam adult population distributions (Fig. 1).
} 
Larval transport is the horizontal dispersal of larvae from one point to another within a certain time interval (Pineda et al., 2007). Larval transport and settlement have long been considered to be primary determinants of dynamics in adult populations (Thorson, 1966), although Ólafsson and colleagues (1994) stressed the importance of post-settlement processes in determining the ultimate influence of larval supply. Nevertheless, post-settlement processes are of no consequence without larval supply and thus connectivity among different geographically distributed subpopulations leading to source and sink dynamics becomes an important component of the dynamics of a metapopulation. Knowledge of governing processes and mechanisms affecting larval transport and settlement is fundamental in understanding the population structure of marine sessile invertebrates, and more broadly to predict the effects of global climate change on benthic marine ecosystems (Condie et al., 2005; Gawarkiewicz et al., 2007; Munroe et al., 2012; Swearer et al., 2002). Processes on a broad range of temporal and spatial scales can impact coastal currents and thereby larval transport. For nearshore systems, a variety of region-specific processes such as along-shelf cold/warm currents (Hickey, 1979; Leaman et al., 1989), coastal upwelling/downwelling (Garland and Zimmer, 2002; Garland et al., 2002; Ma, 2005; Ma and Grassle, 2004; Ma et al., 2006; Shanks et al., 2002; Shanks et al., 2003), shelf break fronts (Marra et al., 1990; Munk et al., 1995), tidal induced mixing fronts (Smith and Morse, 1985), seasonal changes in shelf stratification (Aikman and Posmentier, 1985), and seasonal evolution of the "cold pool" (Houghton et al., 1982), may influence, and potentially dominate, the dynamics of larval transport. Unlike water parcels which only flow passively with the surrounding currents, marine larvae generally have some degree of behavior (Dekshenieks et al., 1996; Hill, 1991; Pfeiffer-Hoyt and McManus, 2005), such as swimming, growth, ontogenetic changes in sinking rate, and selection of substrates before settlement, which are observed for many invertebrates to be essential factors in determining the dynamics of larval transport and spatial variations in settlement (Lough et al., 2005; Werner et al., 1993).

The Atlantic surfclam (hereafter surfclam), Spisula solidissima, is a bivalve mollusk with a life history that includes a planktotrophic larval dispersal stage and a sessile juvenile/adult stage. Surfclam adults inhabit waters from Cape Hatteras, North Carolina to the southern Gulf of St. Lawrence, in a depth range from shallow subtidal regions to around the 60 meter isobath (Cargnelli et al., 1999; Ropes, 1980), depending on bottom water temperature (Kim and Powell, 2004; 
Weinberg et al., 2005). Most of the surfclam population exists today on the Middle Atlantic Bight (MAB) shelf and Georges Bank (GBK) (Fig. 1), where it supports a high-value commercial fishery (NEFSC, 2010). Studying spatial and temporal variations in surfclam larval transport and the underlying mechanisms is essential for better understanding surfclam population dynamics, formulating improved management decisions for the surfclam fishery, and interpreting associated socio-ecological responses to climate change (McCay et al., 2011).

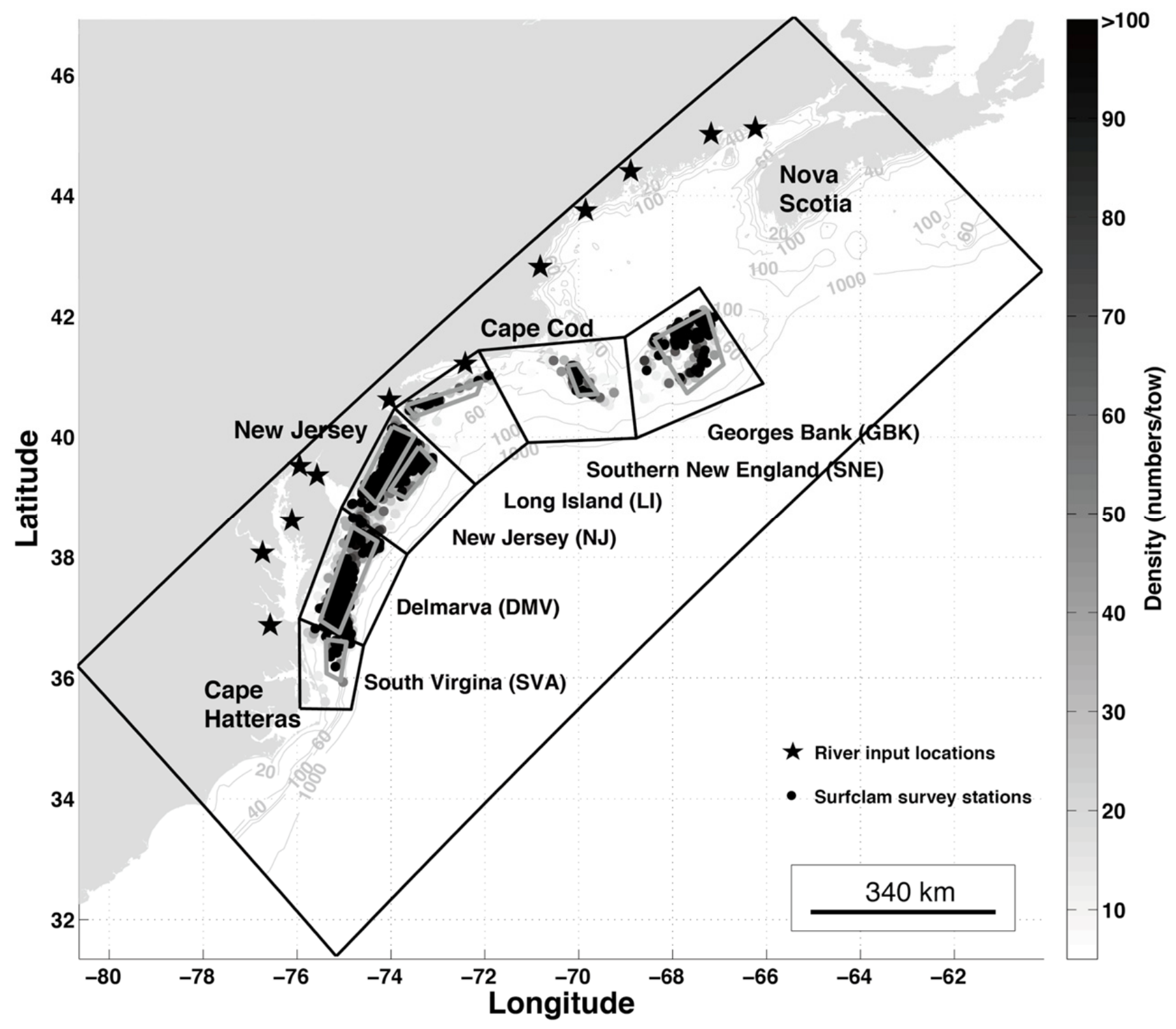

Figure 1. Model domain and distribution of surfclam populations within the Middle Atlantic Bight and Georges Bank. The model domain (large black box) is $160 \times 120$ grid squares and includes 12 river input locations (black stars). Grid resolution 
ranges from 6 to $12 \mathrm{~km}$ (the resolution varies south to north because of the curvature of the earth). Distribution of surfclams in the domain was based on the NEFSC survey data from 1982 to 2008 (NEFSC, 2010). Each dot represents a survey station, with values of surfclam density (numbers/tow) indicated by the colorbar on the right. Values $>100$ clams/tow are grouped into the highest category $(>100)$. Black neighboring boxes represent geographic regions used for surfclam stock assessments (NEFSC, 2010); these are, from south to north: South Virginia/North Carolina (SVA), Delmarva (DMV), New Jersey (NJ), Long Island (LI), Southern New England (SNE) and Georges Bank (GBK). Gray boxes denote regions of high surfclam density and are used as the larval release regions in the model. Isobaths of 20,40,60, 100, and 1000 meters are shown as gray solid lines.

The fishery stock region (the MAB and GBK) is the focal region for this study which examines variations in surfclam larval transport and settlement. The MAB is a shallow and wide continental shelf bounded by Cape Hatteras in the south and Cape Cod in the north (Fig. 1). The MAB exhibits a time- mean, depth-averaged, along-shore current of 5-10 $\mathrm{cm} \mathrm{s}^{-1}$ equatorward with a nearly constant flow along isobaths, and a net but relatively weak across-shelf circulation (Beardsley and Boicourt, 1981; Lentz, 2008a). Large variations in the flow, both in the along-shore and across-shelf directions, exist and are well documented (Gong et al., 2010; Kohut et al., 2004; Shearman and Lentz, 2003; Ullman and Codiga, 2004). Various factors potentially contribute to the those variations, including wind stress (Dzwonkowski et al., 2009; Gong et al., 2010; Kohut et al., 2004), topography (Gong et al., 2010; Harris et al., 2003), seasonal stratification (Dzwonkowski et al., 2009; Shearman and Lentz, 2003), and river plumes (Fong and Geyer, 2002; Zhang et al., 2009). Surfclam larvae, like most larvae in the ocean, are transported passively in the horizontal plane, being subject to the influences of factors affecting bulk flow. In addition, surfclam larval behavior, such as vertical swimming, also influences the horizontal trajectories. By active movement, larvae are able to modulate the water properties they experience and thus their growth history (Zhang et al., 2015) . One objective of this study is to identify the primary mechanisms controlling the dispersal patterns of surfclam larvae in the MAB and GBK.

Observational studies of surfclam larval transport within the MAB are few. Ma et al. (2005; 2004; 2006) examined larval vertical distributions along a cross-shelf transect off Tuckerton, New Jersey, during summer upwelling and downwelling episodes. Studies by Garland and Zimmer (2002), Garland et al. (2002), Shanks et al. (2002), and Shanks et al. (2003) examined the vertical dispersion and across-shelf transport of various species including surfclam larvae across the shelf off of the 
Outer Banks of North Carolina, also under upwelling and downwelling conditions. Interestingly, these studies show contrasting vertical patterns and across-shelf transport on the New Jersey and North Carolina shelves for surfclam larvae. In New Jersey in July of 1997 and 1998, concentrations of surfclam larvae were observed more inshore, near the intersection of the thermocline and the bottom during downwelling, and more offshore, close to or above the thermocline during welldeveloped upwelling (Ma et al. 2005). Larval concentrations were correlated positively with water temperature at this time, indicating that larvae were more likely to be transported by the water above the thermocline. Off North Carolina in August of 1994, surfclam larvae were mostly found below the pycnocline in the bottom layer, with larval concentrations correlating negatively with water temperature (Shanks et al., 2002). During upwelling, larvae were transported onshore by advection of subpycnocline waters, while during downwelling larvae were transported offshore (Shanks et al., 2002, 2003). Ma (2005) speculated that these differences in larval vertical distribution and across-shelf transport between the NJ and SVA shelves might be due to the difference in larval sources, whether from inshore or offshore, as this is related to the larval vertical distribution and their across-shore transport patterns. In this study, the vertical distribution and across-shelf transport patterns of surfclam larvae will be examined for different regions of the MAB and GBK using a coupled physical and biological model, to test if observed patterns can be reproduced using a coupled bio-physical model and to determine the underlying mechanisms generating these patterns.

The main objective of this study is to investigate intra-annual variations of larval transport and settlement of surfclams in the MAB and GBK and the associated underlying physical and behavioral mechanisms producing the variability. In the following, the coupled bio-physical model is introduced, simulations are described, and analytical methods for processing model output are explained. Simulated surfclam larval transport and settlement results are presented and discussed in the context of seasonal shelf processes and larval depth distribution.

\section{Methods}

\subsection{Coupled physical circulation and larval biological model}

\subsubsection{The Coupled Model}


A physical circulation model based on the Regional Ocean Modeling System (ROMS) and a surfclam larval individual-based model have been developed, coupled, and validated. The coupled physical circulation and surfclam larval model was run for year 2006 to examine intra-annual variations in larval transport and settlement. Year 2006 was taken as a representative year based on Zhang et al. (2015) who consider interannual variations in larval distributions as a function of the interannual variations in the hydrodynamic regime. A full model description is provided in Zhang et al. (2015), consequently a shortened description is provided here.

The domain for the physical circulation model covers the entire Middle Atlantic Bight, Georges Bank, and the Gulf of Maine, including regions with high surfclam abundance (Fig. 1). The model was forced by real-time solar radiation (National Centers for Environmental Prediction, NCEP), wind (NCEP), river discharge (U.S. Geological Survey, USGS), and tides (ADvanced CIRCulation model, ADCIRC). The oceanic lateral boundary conditions are provided with verified corrections from a larger-scale circulation model with verified corrections (Bleck, 2002).

The surfclam larval model has two main components: larval growth and vertical swimming behavior. Larvae grow after release, with the growth rate expressed as a function of water temperature (Wright et al., 1983; Roosenburg et al., 1984; Hurley and Walker, 1997), larval age and food concentration, although food concentration was assumed to be invariant in these simulations. Comprehensive information on larval food supply is not available for the MAB; hence the model was run under the assumption that food supply did not limit larval growth. Larvae are variously affected by periods of suboptimal food (e.g., Moran and Manahan, 2004; Powell et al., 2002; Przeslawski and Webb, 2009) and this can influence survival and location of settlement because larval growth frequently may be food-limited (Bos et al., 2006; Gireesh and Gopinathan, 2008; Olson and Olson, 1989). Thus, our simulations under this assumption represent results under optimal food conditions in the MAB. Larvae become competent to settle at $260 \mu \mathrm{m}$ and settle when they reach the bottom (Fay et al. 1983). The maximum larval life span is set to be 35 days in the plankton; given planktonic mortality (Rumrill, 1990) few larvae are assumed to survive beyond day 35 and metamorphosis generally occurs from 19 to 35 days after spawning depending on water temperature (Fay et al., 1983). 
Vertical movement of the larva depend on the sinking rate (Sk), the upward (USS) and downward (DSS) swimming speeds which are a function of length (Len), the fraction of time spent swimming upward (Usf) or downward (1-Usf), which is a function of temperature (T). Larvae do not swim constantly, therefore the fraction of time swimming (Stf) is set at 92.5\%. Combining all of these elements, the net vertical $(Z)$ speed is:

$$
\frac{d Z}{d t}=S k(\text { Len }) \times(1-S t f)+S t f \times[U s s(\text { Len }) \times U s f(T)-D s s(\text { Len }) \times(1-U s f(T))]
$$

Sinking rate is a function of weight, which is a power function of length:

$$
\operatorname{Sk}(\text { Len })=0.000222 \times \operatorname{Len}^{1.744}
$$

The upward (Uss) and downward (Dss) swimming speeds are quadratic functions of length:

$$
\text { Uss }(\text { Len })=-0.381+0.009262 \times \text { Len }-0.00002692 \times \text { Len }^{2}
$$

and

$$
\operatorname{Dss}(\text { Len })=-0.561+0.01749 \times \text { Len }-0.00006538 \times \text { Len }^{2}
$$

We assume that larvae respond to ambient temperature, not the vertical gradient in temperature. Thus, the fraction of swimming time spent swimming upwards depends on the ambient temperature:

$$
U s f(T)=0.5\left[1-\tanh \left(\frac{T-21}{0.9}\right)\right]
$$

No daily mortality is applied to larvae, and larvae drift passively in the horizontal by means of the surrounding water currents. In contrast, vertical movement of larvae is the sum of sub-grid vertical mixing implemented as a vertical random walk and swimming behavior exhibited by the larvae, with the speed and direction being functions of water temperature and larval size (Mann et al., 1991). The parameters used in the larval model were obtained and calibrated from laboratory experiments, with detailed descriptions provided in Zhang et al. (2015).

\subsubsection{Larval Release}

Surfclam larvae are released from regions with high surfclam abundances identified using the 1982-2008 NEFSC surfclam stock surveys (NEFSC, 2010). From south to north these regions 
are: South Virginia/North Carolina (SVA), Delmarva (DMV), New Jersey inshore (NJ_in), New Jersey offshore (NJ_off), Long Island (LI), Southern New England (SNE), and Georges Bank (GBK) (Fig. 1). The number of larvae released in each region is proportional to both the historically observed surfclam density and the regional area. As a result, 400, 2000, 1800, 300, 400, 400 and 1500 larvae were released within the SVA, DMV, NJ_in, NJ_off, LI, SNE, and GBK regions, respectively, at each release event. The spawning time of surfclams generally ranges from late spring (late May or June) until fall (Cargnelli et al., 1999; Fay et al., 1983; Jones, 1981; Ropes, 1968), so the release times for surfclam larvae in the model were chosen to be from May $21^{\text {st }}$ until October $16^{\text {th }}$ at 5 -day intervals throughout the spawning season. In total, 30 releases and 204,000 larvae (6,800 per release) were generated, covering the entire spawning season and also the main surfclam spawning areas along the U.S northeastern shelf.

\subsection{Model output data analysis}

\subsubsection{Drifting Distance}

To study surfclam subpopulation connectivity (see section 2.3), it is important to consider larval net drifting distance. This was computed by comparing the initial larval release position with the final larval settlement position or the position at the end of life span if not settled by then. Within each region, the along-shore and across-shelf directions were determined with reference to the along-shore line as indicated in Figure 2. Thus, the along-shore larval drift distance is the length of the larval trajectory parallel to the along-shore reference line, while the across-shelf larval drift distance is the net displacement from initial release position perpendicular to the along-shore line. Regional mean of net along-shore and across-shelf larval drifting distances among all larvae released from each region at each time were computed. Regional means exclude those larvae that drift into regions with water depths exceeding 100 meters, where they were assumed to be unable to find suitable settlement habitat (Zhang et al., 2015) . 


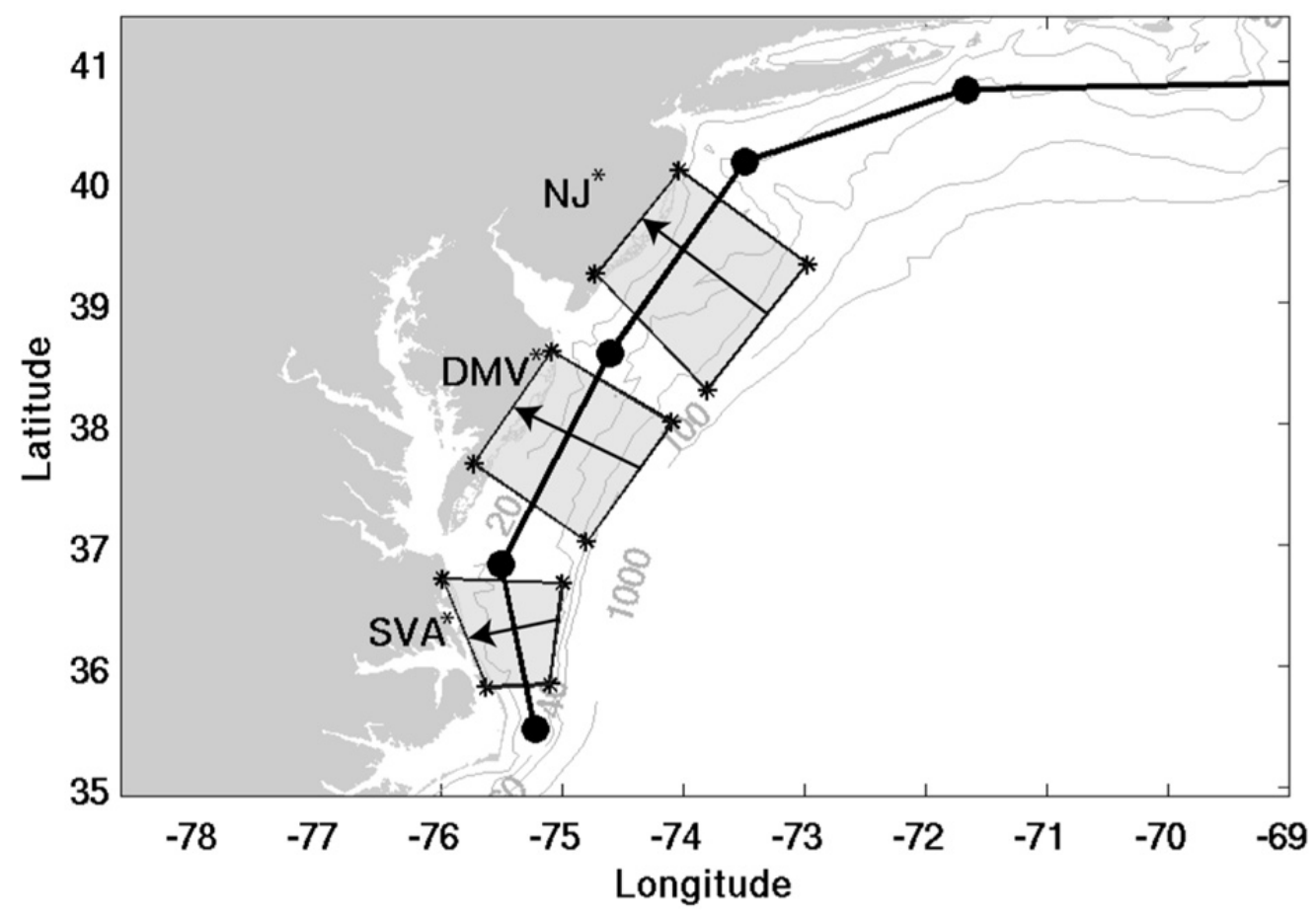

Figure 2. Map of the $\mathrm{NJ}^{*}, \mathrm{DMV}^{*}$, and $\mathrm{SVA}^{*}$ shelf regions (shaded) used for analysis of variation in the along-shore and acrossshelf larval daily movement. These regions cover the corresponding shelves from the coast to at least the 60 meter isobath. The heavy black-dot-line indicates the approximate along-shore direction, while the perpendicular black arrows indicate acrossshore inshore directions. The larval along-shore, across-shelf daily drifting distances and wind stresses in the along-shore and across-shelf directions are calculated. The 20, 40,60, 100 and 1000 meter isobaths are shown with gray lines.

\subsubsection{Settlement Rate and Temperature}

Larval settlement rate was defined as the ratio of successful settlers with respect to the total number of larvae released for each release from each region. The final determination of whether the larvae successfully settle requires that two conditions be satisfied: first, that the larvae reach settlement size within 35 days, and second, that the horizontal location of settlement be shallower than 60 meters as is generally the case for adult surfclam habitats (see section 1). The larval average temperature, i.e. the mean temperature experienced by the larvae during the entire life stage, was calculated for all larvae released from each region, excluding those larvae that are transported into regions with water depths exceeding 100 meters depth.

\subsubsection{Daily Dispersal and Surface Winds}


To examine the relationship between surface winds and variations in larval transport, daily larval movement and surface wind forcing were calculated. Larval daily drifting distance was calculated as the net change in position within each day, then added over larval stage to form the total larval transport. The mean along-shore and across-shelf daily drifting distances were computed among larvae within each of three regions $\left(\mathrm{NJ}^{*}\right.$, DMV*, and $\mathrm{SVA}^{*}$; see Figure 2) on each day, regardless of where and when they were released. Note that the SVA* region chosen here approximates the North Carolina shelf region from observational studies (Garland and Zimmer, 2002; Garland et al., 2002; Shanks et al., 2002; Shanks et al., 2003). The daily mean surface wind stress was computed as the mean of the surface wind stresses experienced by larvae within each region on each day. The approximate along-shore line, as indicated in Figure 2, is used as the reference direction for the calculation of along-shore and across-shelf daily larval drifting distances and wind stresses.

\subsection{Physical and Behavioral Mechanisms Driving Dispersal and Settlement Variability*}

As described in sections 2.2.1 and 2.2.2, larval net along-shore and across-shelf drifting distances, larval average temperature, larval settlement rate and their regional means were compiled. Spatial and temporal variations in larval drifting distances, average temperature and settlement rate were examined. The relationship between larval settlement rate and larval average temperature was also examined.

The impact of along-shore wind forcing on the larval along-shore drift was examined by investigating the relationship between the mean along-shore larval daily drifting distances $\left(d_{-} a l\right)$ and the mean along-shore surface wind stress (wstr_al) for three regions: $\mathrm{NJ}^{*}, \mathrm{DMV}^{*}$ and SVA*, as introduced in section 2.2.3. To examine the inshore and offshore dependence of this relationship, the shelf was further separated into the inner shelf (depth $<30 \mathrm{~m}$ ) and the outer shelf (depth $>30$ $\mathrm{m})$, and the same calculations were made for wstr_al and $d_{-} a l$. The 30 meter depth threshold was

\footnotetext{
* Abbreviations used in this section: $d \_a l$ : along-shore larval daily drifting distances; $d$ _cr: across-shore larval daily drifting distances; wstr_al: along-shore surface wind stress.
} 
chosen here to approximate the mid-point of the shelf region assumed to represent suitable surfclam habitat.

The impact of along-shore wind forcing to the larval across-shore drift was also examined by investigating the relationship between the mean larval daily across-shelf drifting distances $\left(d_{-} c r\right)$ and the mean along-shore surface wind stress (wstr_al). A stratification index was calculated as the ratio of the temperature difference between surface and bottom with respect to the water column thickness, in units of ${ }^{\circ} \mathrm{C} / \mathrm{m}$. The relationship between $d_{-} c r$ and $w s t r$ al is examined when stratification is greater than $0.2{ }^{\circ} \mathrm{C} / \mathrm{m}$. Inshore larvae are used for comparison with available surfclam larval observations from the inner $\mathrm{NJ}^{*}$ and $\mathrm{SVA}^{*}$ shelves (Ma et al., 2006; Shanks et al., 2002; Shanks et al., 2003).

\section{Results}

\subsection{Seasonal Variation in Larval Transport and Settlement}

Larvae released from different source populations at different times experience different larval settlement rates. Larval releases from LI experience higher settlement rates when occurring from mid July to Late September. Larvae released from NJ tend to be more successful later in the year, from early August to late September, and larvae from DMV later still, from early September to early October (Fig. 3b-2). Overall, larvae released from LI, NJ, and DMV experience higher settlement rates than other regions (Fig. 3b-2, 3b-3), whereas, larvae released from late July to late September have higher settlement rates than those at other time periods (Fig. 3b-1).

The spatial and temporal patterns of larval average temperature are similar to those of the settlement rate (Fig. 3a-2). Larval releases with relatively larger average temperature experience higher settlement rates. The black lines in Figure 3 panels a- 2 and b-2 enclose those larval releases experiencing average temperature higher than $18^{\circ} \mathrm{C}$; $98 \%$ of these releases have greater than $60 \%$ settlement success (Fig. 3b-2). The relationship between larval average temperature and settlement rate is correlative, but is not necessarily deterministic as some releases experience average temperature greater than $18^{\circ} \mathrm{C}$, yet have low settlement success mostly due to dispersal to 
inappropriate regions. For instance, for those larval releases from DMV and SVA, most of the "unsuccessful" larvae were entrained into the Gulf Stream and transported out of suitable habitat into the open ocean and thereby into waters too deep for survival.

Along-shore and across-shelf total drifting distances also vary both spatially and temporally. Along-shore larval drift is typically in the southwestward direction (Fig. 3c-2). Larvae released during August on average experience relatively longer southwestward drift, around $200 \mathrm{~km} \mathrm{(Fig.} \mathrm{3c-}$ 1), than those released at other times, whereas releases from NJ, DMV and SVA drift farther than those from other regions, with an average drift of 120 150 km (Fig. 3c-3). The longest along-shore southwestward drift, at around $220 \mathrm{~km}$, was observed for releases during August from LI, NJ, DMV and SVA (Fig. 3c-2). Larvae released from NJ, DMV and SVA experience net total inshore transport on most release dates, whereas those released from LI, SNE and GBK generally experience net total offshore transport (Fig. 3d-2, d-3). The net larval onshore drifting distances are generally larger for releases during July and August than for releases at other times (Fig. 3d-1), with the maximum value close to $40 \mathrm{~km}$ for some releases from NJ, DMV and SVA (Fig. 3d-2). Larval releases from GBK experience relatively different patterns of along-shore and across-shore transport due to its special clockwise circulation around the bank (Backus, 1987), and will not be the main focus in this paper.

All of the trends in regional mean larval dispersal relative to average temperature, settlement rate, along-shore and across-shore drifting distance are characterized by high variability, both temporally and spatially among different release regions (Figure 3). This variability is related to intrinsic fine-scale processes (e.g., vertical turbulent mixing, parameterized here by a random walk) that themselves vary rapidly in space and time. The variability among larval drift distances in time and space is explored statistically in the following sections. 

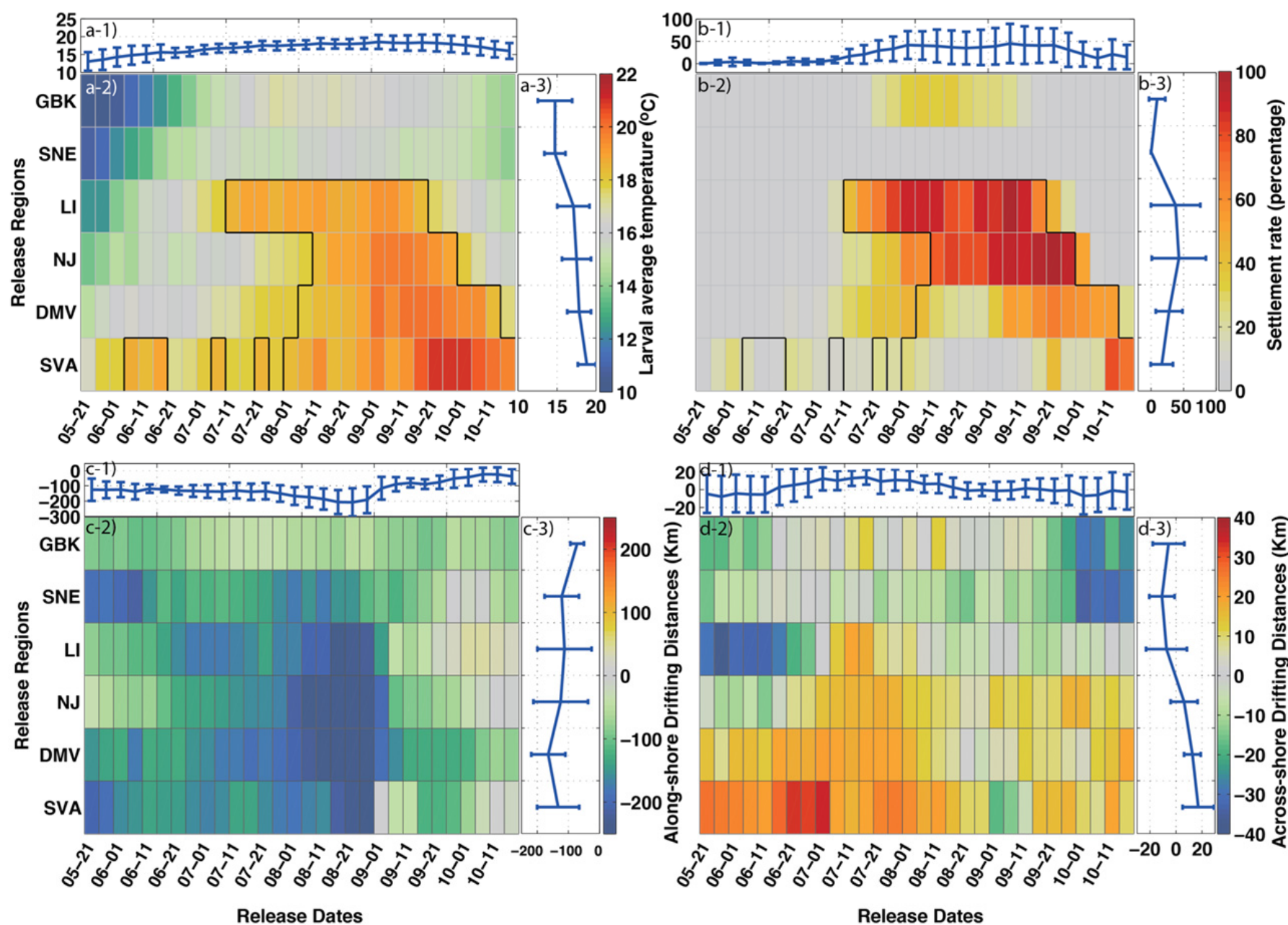

Figure 3. Intra-annual and spatial variations of larval average temperature $\left({ }^{\circ} \mathrm{C}\right.$, Panel a-2), larval settlement rate $(\%$, Panel b-2), along-shore larval drifting distances ( $\mathrm{km}$, positive values indicate along-shore northeastward drifting, Panel $\mathrm{c}-2)$ and acrossshelf larval drifting distances ( $\mathrm{km}$, positive values indicate onshore drifting, Panel $\mathrm{d}-2)$ for larvae released from different regions (y-axis) at different times (x-axis) in 2006. The black lines in panels a-2 and b-2 enclose those larval releases with average temperature higher than $18^{\circ} \mathrm{C}$. Panels above (a-1, b-1, c-1 and d-1) show the mean of each variable among all regions at each release time (+/- standard deviation), and panels at right (a-3, b-3, c-3 and d-3) show the mean among releases at all times from each region (+/- standard deviation),

\subsection{Along-shore Daily Drift}

Temporal variations in the mean along-shore daily drifting distances $\left(d_{-} a l\right)$ and along-shore surface wind stresses (wstr_al) on the $\mathrm{NJ}^{*}$ shelf are highly correlated (Pearson's $r=0.60$, Fig. 4a, Table 1). A linear regression model (M1) between $d_{-} a l$ and wstr_al was fitted and the model explains $36 \%$ of the total variance in the daily drifting distances, $d_{-} a l$. The model-predicted value is indicated 
by $d \_a l \_m 1$. A plot of the residuals of this fitted linear model (res $=d \_a l-d \_a l \_m 1$ ) shows a noticeable seasonal signal (Fig. 4b, gray line). The least-squares best fit to res using results of a seasonal model (M2) shows a significant seasonal cycle with a 147.4-d period and a $4.21 \mathrm{~km}$ amplitude (Fig. 4b, black line; Table 1). Within the seasonal signal, the minimum value appears in mid-August corresponding to the longest southwestward drift, and the maximum occurs at the end of October corresponding to the least southwestward, or in some cases a northeastward, drift (Fig. $4 \mathrm{a}, \mathrm{b})$. The simulated seasonal signal (d_al_m2) explains about $28 \%$ of the total variance of the daily drifting distances, $d \_a l$ (Table 1). Together, the linear regression model (M1) and the seasonal model (M2) contribute $64 \%$ of the total variance of the mean along-shore larval daily drifting distances $\left(d_{-} a l\right)$.

The same analysis, using the linear regression model (M1) and the seasonal model (M2), was applied to larvae on the $\mathrm{DMV}^{*}$ and $\mathrm{SVA}^{*}$ shelves (Table 1). On both the $\mathrm{DMV}^{*}$ and $\mathrm{SVA}^{*}$ shelves, the surface along-shore wind stress (wstr_al) and the along-shore larval daily drift ( $d_{-} a l$ ) were highly correlated (Pearson's $r=0.65$ and 0.61 respectively). The linear fitted regression models (M1) between $d_{-} a l$ and wstr_al explain $42 \%$ and $38 \%$ of the variance of $d_{-} a l$ for larvae within $\mathrm{DMV}^{*}$ and SVA $^{*}$ shelves respectively. The least-squares best fit of a seasonal model to the linear regression model residuals shows a significant ( $\mathrm{p}$-value $<0.001$ ) seasonal signal with a period of 159 days on the $\mathrm{DMV}^{*}$ shelf, with a variance contribution of $10 \%$ to the total $d \_a l$ variance. Together, models M1 and M2 contribute 52\%. On the SVA* shelf, however, the seasonal signal within the linear model residuals is not significant.

For larvae inshore of 30 meters and offshore of 30 meters respectively, high correlations between the surface along-shore wind stress (wstr_al) and along-shore larval daily drift $\left(d_{-} a l\right)$ are found for the $\mathrm{NJ}^{*}, \mathrm{DMV}^{*}$, and $\mathrm{SVA}^{*}$ regions. After the wind-induced components of $d_{-} a l$ are removed, the residuals show a significant seasonal signal for both inshore and offshore larvae on both the $\mathrm{NJ}^{*}$ and $\mathrm{DMV}^{*}$ shelves, but with a phase difference from inshore to offshore. For example, inshore $\mathrm{NJ}^{*}$ larvae experience maximum southwestward drift on August $6^{\text {th }}$, whereas the maximum occurs on August $24^{\text {th }}$ for the offshore larvae (Fig. 4c). A statistically significant (Welch's $t$-test, p-value $<0.001$ ) forward phase shift in the seasonal signal occurs for the offshore larvae relative to those inshore. A 
similar trend in forward phase shift from inshore to offshore larvae is also found on the DMV ${ }^{*}$ shelf (not plotted). 
Table 1. Linear regression and seasonal models of along-shore larval daily drifting distances

\begin{tabular}{|c|c|c|c|c|c|c|c|c|c|}
\hline \multirow{3}{*}{ Regions } & \multicolumn{5}{|c|}{ Linear regression model (M1) a } & \multicolumn{4}{|c|}{ Seasonal model (M2) b } \\
\hline & \multirow{2}{*}{$\begin{array}{l}\text { Pearson's } \\
\text { Correlation } \\
\text { coefficient c }\end{array}$} & \multicolumn{2}{|c|}{$\begin{array}{l}\text { Model parameters } \pm 95 \% \\
\text { confidence intervals }\end{array}$} & \multirow{2}{*}{$\begin{array}{c}\text { Ratio of } \\
\text { Variance } \\
\text { Explainedd }\end{array}$} & \multirow{2}{*}{ p-value } & \multicolumn{2}{|c|}{$\begin{array}{c}\text { Model parameters } \pm 95 \% \\
\text { confidence intervals }\end{array}$} & \multirow{2}{*}{$\begin{array}{c}\text { Ratio of } \\
\text { Variance } \\
\text { Explainedd }^{\text {D }}\end{array}$} & \multirow{2}{*}{ p-value } \\
\hline & & Intercept $(B 1)$ & Coefficient (B2) & & & Amplitude $(A$, in $\mathrm{km})$ & Period ( $T$, in days) & & \\
\hline $\mathrm{NJ}^{*}$ shelf & 0.60 & $-4.45 \pm 0.70$ & $95.39 \pm 19.74$ & 0.357 & $<0.001$ & $4.21 \pm 0.74$ & $147.4 \pm 12.45$ & 0.282 & $<0.001$ \\
\hline $\mathrm{DMV}^{*}$ shelf & 0.65 & $-6.36 \pm 0.93$ & $143.40 \pm 25.74$ & 0.419 & $<0.001$ & $3.50 \pm 1.17$ & $159.2 \pm 32.93$ & 0.101 & $<0.001$ \\
\hline SVA $^{*}$ shelf & 0.61 & $-6.29 \pm 1.03$ & $130.07 \pm 25.63$ & 0.373 & $<0.001$ & $1.81 \pm 0.88$ & $174.7 \pm 50.25$ & 0.036 & 0.1007 \\
\hline
\end{tabular}

a. Linear regression models $\left(\mathrm{M} 1: \boldsymbol{d} \_\boldsymbol{a l} \_\mathbf{m 1}=\boldsymbol{B 1}+\boldsymbol{B} \boldsymbol{2} * \boldsymbol{w s t r} \boldsymbol{a} \boldsymbol{l}\right)$ between along-shore larval daily drifting distances $\left(d \_a l\right)$ and along-shore surface wind stress (wstr_al) for larvae in different regions,

b. Seasonal models $\left(\mathrm{M} 2: \boldsymbol{d} \_\boldsymbol{a l} \_\boldsymbol{m} 2=\boldsymbol{A}^{*} \boldsymbol{s i n}\left(\mathbf{2}^{*} \boldsymbol{\pi} / \boldsymbol{T} * \boldsymbol{t}\right)\right)$ of the linear regression model residuals $\left(\right.$ res $\left.=d \_a l-d \_a l \_m 1\right)$ with time $(t$, in days), using the least-squares best fit.

c. Pearson's correlation between the along-shore larval daily drifting distances and the along-shore wind stress in different regions.

d. Explained variance ratio was calculated as the ratio of the variance of model fitted values over the variance of original observations. It was used to measure the proportion to which a mathematical model accounts for the variation (dispersion) of a given data set.

e. Variables included in this table: $w s t r \_a l$, along-shore wind stress; $d \_a l \_m 1$, along-shore larval daily drifting distances simulated by linear regression models; $d \_a l \_m 2$, along-shore larval daily drifting distances simulated by seasonal models; $T$, seasonal cycle period; $t$, days in the year. 


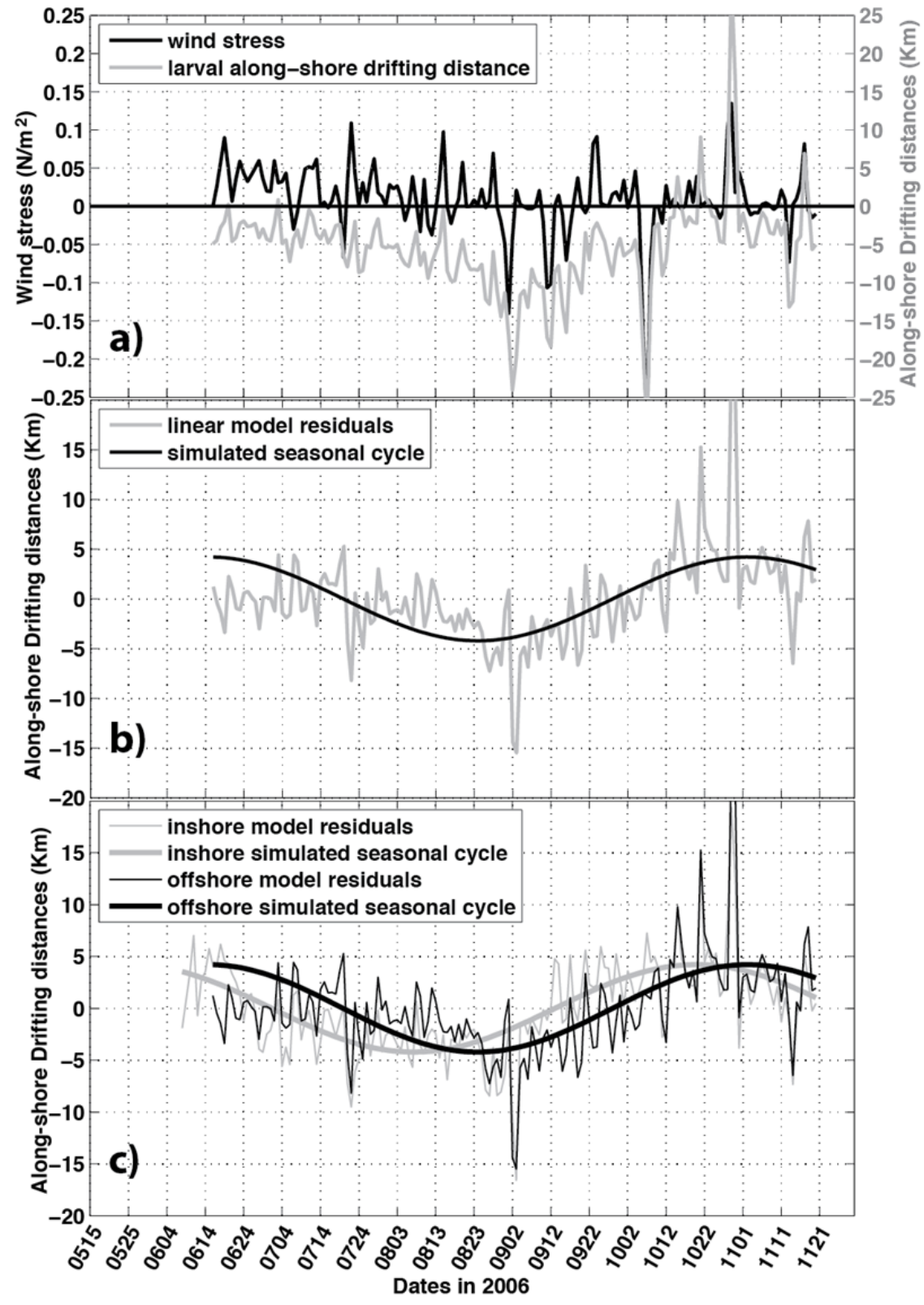

Figure 4. Panel a: Temporal variation of along-shore surface wind stress (wstr_al, black line) and along-shore larval drifting distances (d_al, gray line) for larvae on the $\mathrm{NJ}^{*}$ shelf. Panel b: Linear model residuals with the wind-induced component removed (res, gray line) and the simulated seasonal cycle signal (d_al_m2, black line), for larvae on the $\mathrm{NJ}^{*}$ shelf. Panel c: Linear model residuals $\left(r\right.$, thin lines) and the simulated seasonal cycle signal ( $d \_a l \_m 2$, thick lines), respectively for inshore (0 30 m, gray lines) and offshore (30 60 m, black lines) $\mathrm{NJ}^{*}$ larvae. 


\subsection{Across-shelf Daily Drift}

The mean along-shore surface wind stress (wstr_al) and the mean across-shelf larval daily drifting distance $\left(d_{-} c r\right.$ ) for $\mathrm{NJ}^{*}$ inshore larvae are plotted in Figure 5a. The correlation between these two variables varies in time between negative and positive. A positive correlation indicates that a northward (southward) along-shore surface wind stress corresponds to inshore (offshore) larval daily drifting, whereas a negative correlation indicates that northward (southward) along-shore surface wind stress corresponds to the offshore (inshore) across-shelf larval daily drifting.

Larval vertical distribution in the water column during stratification, whether concentrated in the upper layer or bottom layer, is a critical factor in determining the correlation between $d_{-} c r$ and wstr_al. We use the depth at which the across-shelf current reverses (the reversing depth) as the depth separating the bottom and top layers of the water column. During periods with a stratification index greater than $0.2^{\circ} \mathrm{C} / \mathrm{m}$, roughly June $16^{\text {th }}$ to September $1^{\text {st }}$ on the $\mathrm{NJ}^{*}$ shelf $($ Fig. 5 , shaded period in both gray and blue) or June $11^{\text {th }}$ to September $6^{\text {th }}$ on the SVA shelf (Fig. 6 , shaded period in both gray and blue), the correlation between $d_{-} c r$ and wstr_al is mostly negative when larvae are close to or above the reversing depth, whereas the correlation becomes positive when larvae are below the reversing depth.

For example, on the $\mathrm{NJ}^{*}$ shelf from June $16^{\text {th }}$ until the end of July (Fig. 5, gray-shaded region) the mean larval depth is mostly close to or above the across-shelf current reversing depth and the correlation between $d_{-} c r$ and wstr_al is negative (Pearson's $r=-0.64$ ), whereas in August (Fig. 5, blue-shaded region) the mean larval depth is largely below the reversing depth and the correlation becomes positive (Pearson's $r=0.60$ ). On the $S A^{*}$ shelf from around June $11^{\text {th }}$ to the end of June (Fig. 6, gray-shaded region) when the mean larval depth is mostly above or close to the reversing depth, the correlation between $d_{-} c r$ and wstr_al is negative (Pearson's $r=-0.25$ ), whereas later in the year from July to September $7^{\text {th }}$ (Fig. 6, blue-shaded region) when the mean larval depth is below the reversing depth, the correlation becomes positive (Pearson's $r=0.71$ ). 
A linear regression model (M3) of the effect of wind-stress and of the interaction between wind-stress and depth layer (upper or lower) on the cross-shore drifting distance (d_cr_m3) significantly explains about $53 \%, 52 \%$ and $38 \%$ of the variance $(\mathrm{p}<0.001$ for all) during the stratified season for larvae on the $\mathrm{NJ}^{*}, \mathrm{DMV}^{*}$ and $\mathrm{SVA}^{*}$ shelves respectively (Table 2). The model shows that $d_{-} c r$ correlates negatively with wstr_al when larvae are in the upper layer and positively with wstr_al when larvae are in the bottom layer (Table 2), further emphasizing the importance of larval vertical distribution on larval across-shelf transport. 

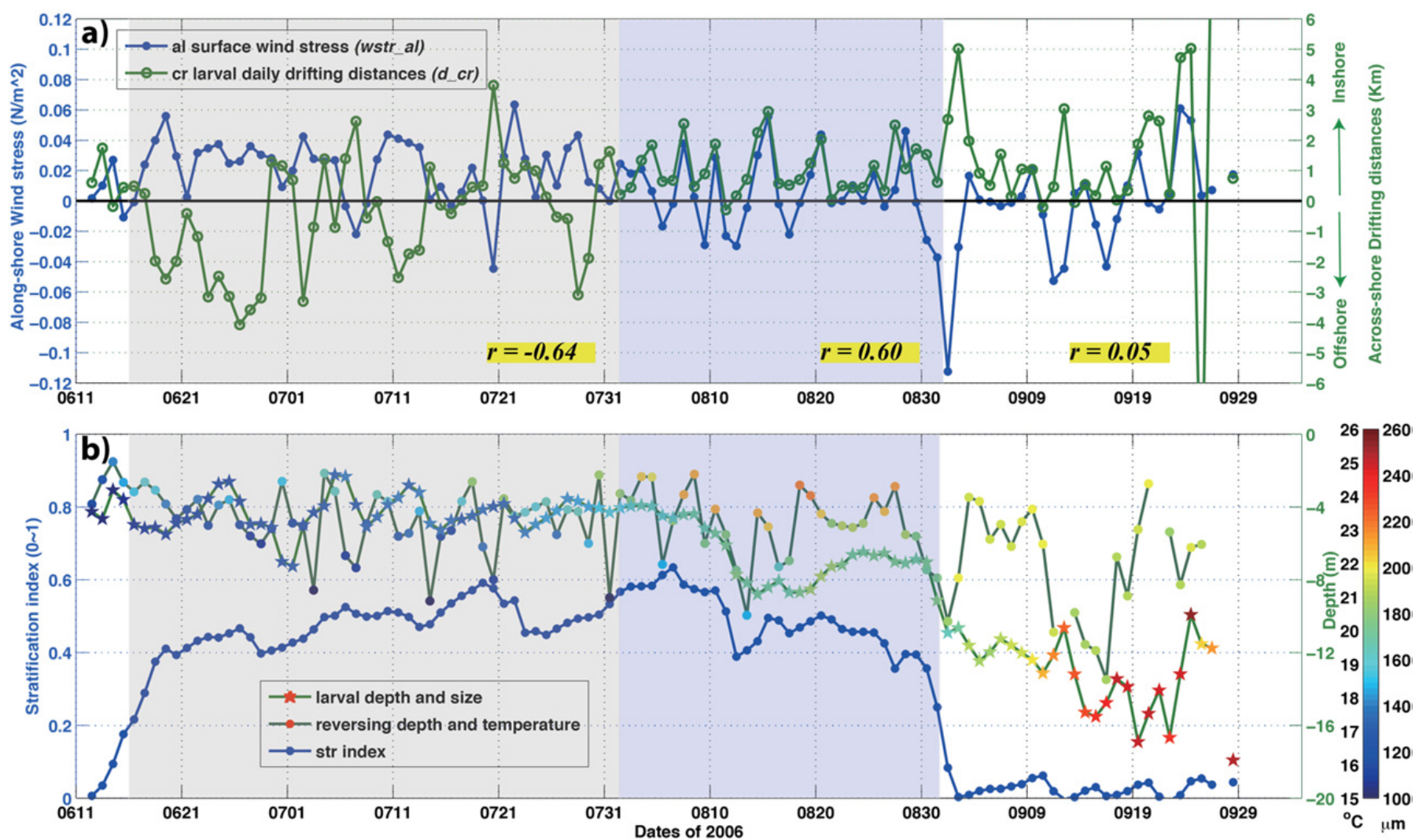

Figure 5. Panel a: Temporal variation in mean along-shore surface wind stress (wstr_al, $\mathrm{N}^{*} \mathrm{~m}^{-2}$, blue line) and across-shelf daily larval drifting distance $\left(d \_c r, \mathrm{~km}\right.$, green line) for larvae on the New Jersey (NJ") inshore shelf (depth $<20 \mathrm{~m}$, Fig. 2). Left $\mathrm{y}$-axis (blue) shows the values of along-shore surface wind stress $\left(\mathrm{N}^{*} \mathrm{~m}^{-2}\right)$, and the right $\mathrm{y}$-axis (green) shows the values of across-shelf daily larval drifting distances $(\mathrm{km})$. Highlighted text labels show the Pearson's correlation coefficients between $d_{-} c r$ and wstr_al within each period. Panel b: Temporal variation in the mean larval depth (colored stars, right axis), mean across-shelf current reversing depth (colored dots, right axis) and mean water stratification index (blue dotted line, left axis) for larvae on the New Jersey $\left(\mathbf{N J}^{*}\right)$ inshore shelf (depth $<20$ m, Fig. 2). Colored stars and dots along the larval and reversing depth curves indicate the mean larval size $(\mu \mathrm{m})$ and water temperatures $\left({ }^{\circ} \mathrm{C}\right)$ at those depths, scaled by the colorbar on the right. In both panels, the $\mathrm{x}$-axis indicates the observation dates in 2006 (note: these are not release dates), and the shaded regions (gray and blue) show the period when the mean larva depth is shallower and deeper (respectively) than the reversing depth. 

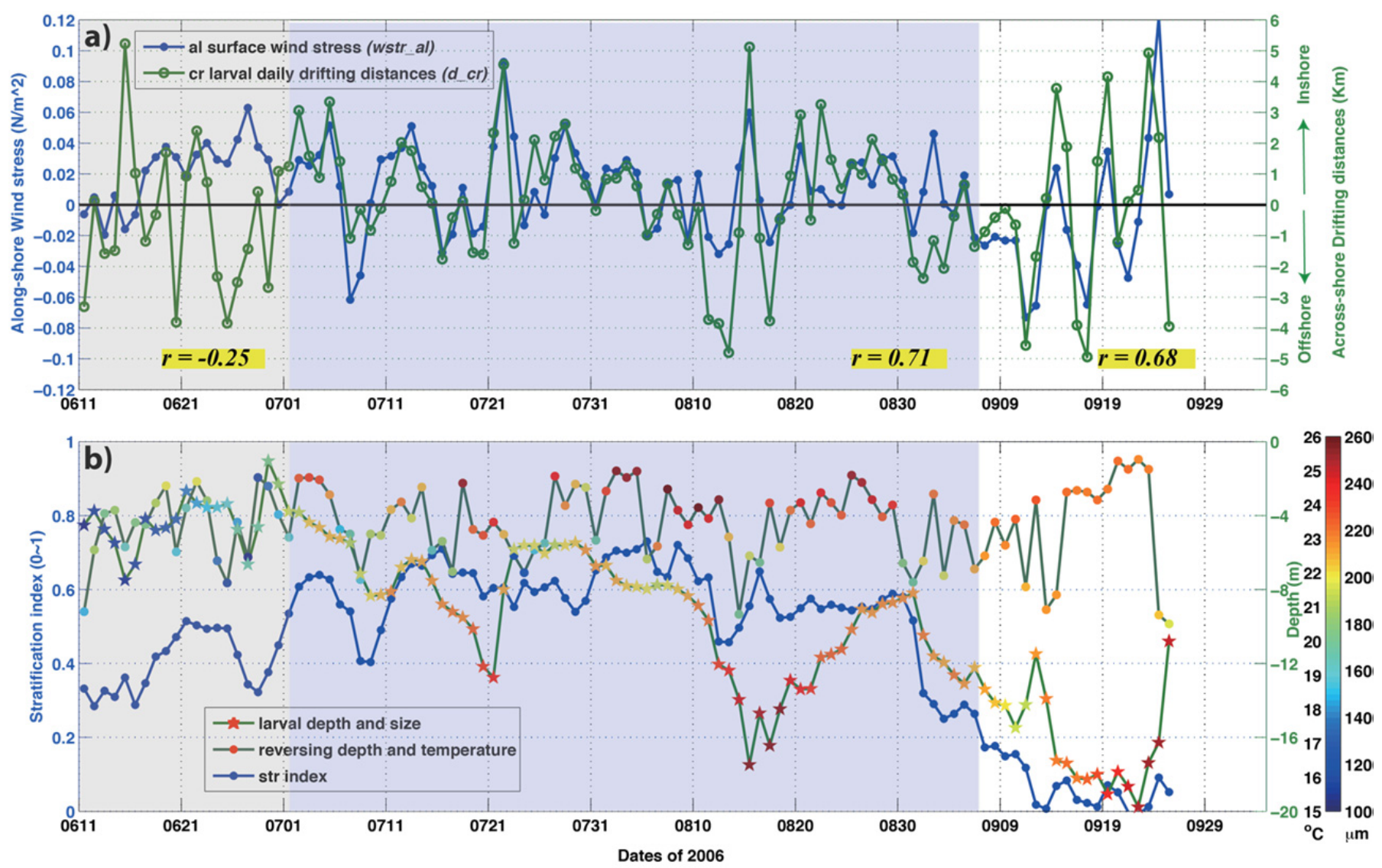

Figure 6. Panel a: Temporal variation in mean along-shore surface wind stress (wstr_al, $\mathrm{N}^{*} \mathrm{~m}^{-2}$, blue line) and across-shelf daily larval drifting distances $\left(d_{-} c r, \mathrm{~km}\right.$, green line) for larvae on the South Virginia (SVA*) inshore shelf (depth $<20 \mathrm{~m}$, Fig. 2). Left $y$-axis (blue) shows the values of along-shore surface wind stress $\left(\mathrm{N}^{*} \mathrm{~m}^{-2}\right)$, and the right $y$-axis (green) shows the values of across-shelf daily larval drifting distances $(\mathrm{km})$. Highlighted text labels show the Pearson's correlation coefficients between $d \_c r$ and wstr_al within each period. Panel b: Temporal variation in the mean larval depth (colored stars, right axis), mean across-shelf current reversing depth (colored dots, right axis) and mean water stratification index (blue dotted line, left axis) for larvae on the South Virginia (SVA*) inshore shelf (depth $<20$ m, Fig. 2). Colored stars and dots along the larval and reversing depth curves indicate the mean larval size $(\mu \mathrm{m})$ and water temperatures $\left({ }^{\circ} \mathrm{C}\right)$ at those depths, scaled by the colorbar on the right. In both panels, the x-axis indicates the observation dates in 2006 (note: these are not release dates), and the shaded regions (gray and blue) show the period when the mean larva depth is shallower and deeper (respectively) than the reversing depth. 
Table 2. The 2-layer linear regression model (M3) of across-shelf larval daily drifting distances for larvae in inshore waters (depth $<20 \mathrm{~m}$ ), using the mean along-shore surface wind stress in different shelf regions. $L_{i}$ is a variable indicating whether larvae are located in the upper layer or bottom layer. $L_{i}=1$ when larvae are in the upper layer, or the larval depth is shallower than the across-shelf current reversing depth; $L_{i}=-1$ when larvae are in the bottom layer, or the larval depth is deeper than the across-shelf current revering depth.

\begin{tabular}{|c|c|c|c|}
\hline Regions & Model Formulation (M3) & $\begin{array}{c}\text { Ratio of Variance } \\
\text { Explained }\end{array}$ & $\mathrm{p}$-value \\
\hline $\mathrm{NJ}^{*}$ shelf & $d_{-} c r_{-} m 3=0.44-35.60^{*} w s t r_{-} a l-38.68^{*} L_{i}{ }^{*}$ wstr_al & 0.53 & $<0.001$ \\
\hline $\mathrm{DMV}^{*}$ shelf & $d_{-} c r_{-} m 3=-0.11+5.36^{*}$ wstr_al $-28.42 * L_{i}{ }^{*}$ wstr_al & 0.52 & $<0.001$ \\
\hline SVA $^{*}$ shelf & $d_{-} c r_{-} m 3=-0.31+2.66^{*} w s t r_{-} a l-40.89 * L_{i}{ }^{*}$ wstr_al & 0.38 & $<0.001$ \\
\hline
\end{tabular}

\section{Discussion}

\subsection{Larval Transport, Settlement, and Regional Connectivity}

A mean downstream connectivity pattern from the northeast to the southwest exists for surfclams in the MAB and GBK (Zhang et al., 2015), yet large variations in the connectivity pattern are also observed, potentially associated with various factors such as larval spawning time and location, larval transport dynamics, planktonic life span, and settlement location (Edwards et al., 2007). Knowledge of connectivity is crucial for better understanding and predicting the ecosystem responses to changing environmental conditions (Gawarkiewicz et al., 2007; GLOBEC, 1991).

In this study, the number of released (spawned) larvae, their distribution at release, and the criteria for successful settlement are invariant. Thus, variations in connectivity mainly originate from variations in larval transport and planktonic life span. As described above, larval life span is an inverse function of larval growth rate, which is mainly determined by the water temperature that the larvae experience. The combined effect of larval transport and life span determines the total larval drift from spawning to final settlement (Pineda et al., 2007), which is equivalent to the connectivity distance between release regions. During summer, relatively longer larval along-shore drift and higher settlement rates associated with higher average temperatures experienced by the larvae indicate broader and more effective connections from source regions to regions downstream. In comparison, larval spawns from late spring to early summer experience relatively shorter alongshore drift and lower settlement rates correlated with lower larval average temperature, indicating 
lower connectivity and an increased waste of spawn at that time. Inshore releases $(<30 \mathrm{~m})$ from LI, NJ and DMV during September to early October experience higher settlement rates and shorter along-shore drift, implying increased self-recruitment for those releases. Relatively high settlement rates for releases from LI and NJ during summer and early fall indicate the importance of both regions as the larval supply sources to local and downstream regions. However, it is also necessary for larvae to experience sufficiently high average temperature during larval dispersal, although this condition in itself is not sufficient to generate a high settlement rate. Larvae must also enter appropriate dispersal currents to reach settlement habitat. For example, larval releases from DMV in summer or from SVA during summer and early fall experience appropriate temperatures, yet low settlement due to the assumed high mortality of those larvae entrained into the Gulf Stream and transported into the open ocean. Studies by Hare et al. (2002); Hare and Cowen (1996) identified a possible return path for those larvae transported into the open ocean back to the shelf via the penetration of Gulf Stream warm core rings onto the shelf. This transport mechanism, however, does not affect the surfclam connectivity pattern calculated herein as almost no surfclam larvae are observed in simulations to be able to get back onto the shelf at suitable habitats within 35 days after being transported off the shelf.

Results in this study show large variations in larval transport and settlement rate closely associated with environmental changes, which further cause large variations in surfclam population connectivity. For better understanding, predicting, and managing surfclam populations in response to the potential effect of climate change, the governing processes and mechanisms causing such variations in larval transport and settlement need to be identified.

\subsection{Along-Shore Transport}

The horizontal swimming speed of surfclam larvae is low in comparison with the horizontal velocity of the water currents; thus in the model larvae are assumed to drift passively in the horizontal direction (Zhang et al., 2015). Consequently, the factors that affect the horizontal current flow within the $M A B$ can be expected to affect the horizontal movement of surfclam larvae. Observations of the along-shore current on the MAB shelf (Lentz, 2008b) show high correlations 
between the along-shore current and the surface wind stress at all observation sites spanning the inner, middle, and outer shelf of the MAB and southern GBK. Seasonal variation of the along-shore current was found to be mainly driven by the across-shelf density gradient, as the direction of most significant seasonal wind variation is approximately perpendicular to the direction of the wind stress that drives the along-shore current. In this study, the results show that larval along-shore movement in $\mathrm{NJ}^{*}, \mathrm{DMV}^{*}$ and $\mathrm{SVA}^{*}$ is highly correlated with the surface along-shore wind stress, which contributes high-frequency variations (periods of $2 \sim 10$ days) in the along-shore daily movement of the larvae.

While the wind-induced component of larval along-shore movement does not show obvious seasonal variations in itself, significant seasonal signals are found in the residuals after the windinduced components are removed from the larval along-shore movement for larvae in $\mathrm{NJ}^{*}$ and $\mathrm{DMV}^{*}$. These significant seasonal signals are speculated to be associated with variation in the across-shelf density gradient. During late summer on the $\mathrm{NJ}^{*}$ shelf, the pycnocline deepens. As a consequence, the more nearshore bottom waters warm up first, while the more offshore bottom waters remain colder due to along-shore "cold" pool advection (Fig. 7a; also Castelao et al. (2008); (Houghton et al., 1982).

Combined with the across-shelf salinity gradient, the fresher warmer nearshore water and the saltier colder offshore water produce a large across-shelf density gradient and therefore a strong along-shore current (Lentz, 2008a). Later in the fall when the water column is well mixed on the shelf (Fig. 7d), the across-shelf density gradient is reduced (Gong et al., 2010). In this study, the maximum (minimum) southwestward larval drift over the seasonal cycle occurs in mid and late August (late October and early November) respectively on the $\mathrm{NJ}^{*}$ and $\mathrm{DMV}^{*}$ shelves (Fig. $4 \mathrm{~b}$ for $\mathrm{NJ}^{*}$, $\mathrm{DMV}^{*}$ not plotted), consistent with the approximate timing of a larger (smaller) across-shelf density gradient and along-shore current. This mechanism also explains the pattern of larval along-shore total transport for larvae released from the LI, NJ and DMV inshore $(<30 \mathrm{~m})$ shelves; that is, those larvae released during September experience a much shorter southwestward drift compared with those released at earlier times, due to the weaker across-shelf density gradient when the water column is well mixed. These results indicate that although variation in the along-shore larval 
transport is dominantly a function of the wind stress, its seasonal modulation is mainly driven by the across-shelf variation in the density gradient.

The model results also show a forward phase shift of the seasonal signal from inshore $\{<30$ $\mathrm{m})$ to offshore $(30 \sim 60 \mathrm{~m})$ on both the $\mathrm{NJ}^{*}$ and $\mathrm{DMV}^{*}$ shelves. Lentz (2008b) found a steady phase increase with water depth of the seasonal variation of the along-shore current offshore of Cape Cod, consistent with the seasonal variation in the across-shelf temperature gradient associated with the "cold pool" development and destruction. On the $\mathrm{NJ}^{*}$ and $\mathrm{DMV}^{*}$ shelves, as the wind stress increases from summer to fall, stronger mixing causes the coastal well-mixed warmer region to expand gradually from inshore to offshore, pushing the position of the mixing front and the maximum across-shelf density gradient offshore (Fig. 7). Thus the inshore waters experience the maximum across-shelf density gradient and the strongest along-shore current relatively earlier than offshore waters, generating a forward phase shift as found in the seasonal signal of along-shore larval drift.

This mechanism also explains the larval total along-shore transport pattern for larvae released from $\mathrm{NJ}$, that is, the larvae released inshore begin to experience longer total along-shore drifting at an earlier time than those released offshore, as those larvae are mostly transported along the NJ or DMV shelves (not shown here). This phase difference between the inshore and offshore larvae in the seasonal signal of their along-shore transport emphasizes the importance of cross-shelf larval position and thus of across-shelf movement of larvae which dictates different along-shore current conditions and thus different along-shore transport and connectivity patterns.

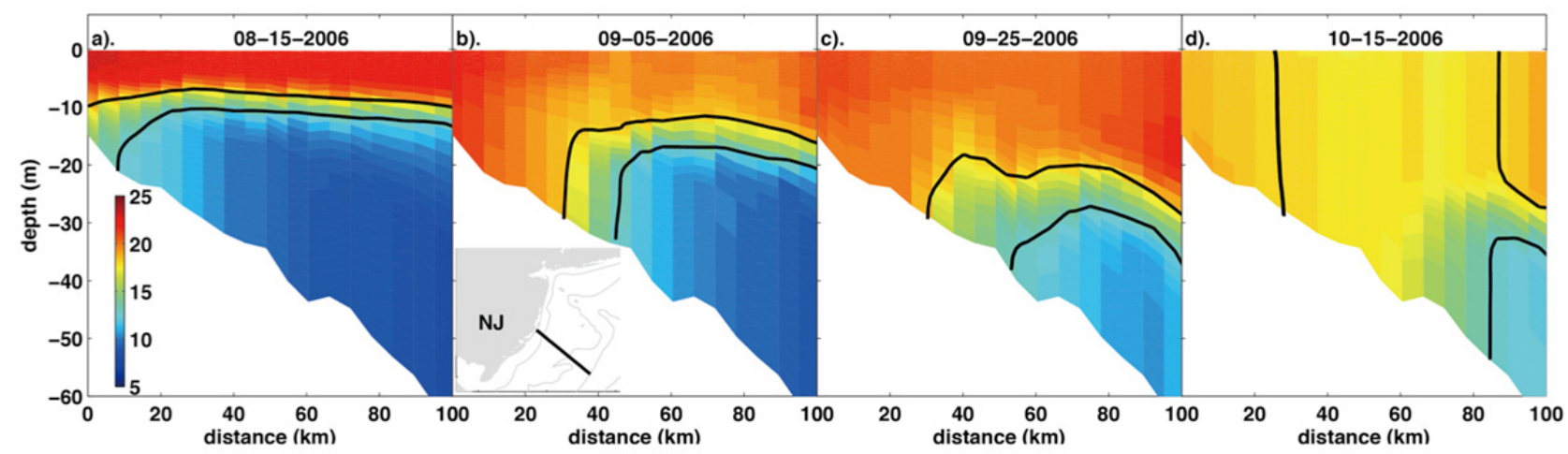

Figure 7. The offshore progression of the mixing front along a transect on the NJ shelf from Aug. $15^{\text {th }}$ (panel a) to Sep. $5^{\text {th }}$ (panel b), Sep. $25^{\text {th }}$ (panel c) and Oct. $15^{\text {th }}$ (panel d) in 2006. The black line in the inset panel (bottom left of panel b) shows the 
location of the NJ across-shelf transect shown in this figure. The across-shelf temperature is shown by the colorbar in the left corner of panel a. X-axis indicates the across-shelf distances $(\mathrm{km})$. Y-axis indicates the water depth $(\mathrm{m})$. The black lines indicate the $18^{\circ} \mathrm{C}$ (upper) and $13^{\circ} \mathrm{C}$ (lower) isotherm lines.

No significant seasonal signal was found for $\mathrm{SVA}^{*}$ in the residuals of larval along-shore drifting distances after the wind-driven component was removed. One possible explanation is that off SVA*, the across-shelf density gradient influences the along-shore current and the degree of larval along-shore drifting, but is not the main factor causing seasonal variations. Strong seasonal variation in the wind-driven along-shore current in $\mathrm{SVA}^{*}$ is evident, as the wind direction driving the along-shore current corresponds to the direction of the largest seasonal wind variation (Lentz, 2008b). In this study, the wind-induced larval along-shore drifting distances have significant seasonal variability, and the removal of wind contribution from the original data removes or reduces the seasonal signal in the residuals of larval along-shore drift.

\subsection{Across-Shelf Movement}

During periods of stratification on the MAB shelf, a wind-driven across-shelf circulation pattern consistent with coastal upwelling/downwelling episodes is well documented; that is, the upwelling (downwelling) favorable wind causes surface layer offshore (onshore) transport and bottom layer onshore (offshore) transport (Dzwonkowski et al., 2009; Gong et al., 2010; Kohut et al., 2004; Lentz, 2001). Surfclam larvae are transported passively in the horizontal direction, thus their across-shelf transport is expected to follow the across-shelf circulation. Larval vertical swimming behavior, however, is critical in determining the larval across-shelf transport pattern by modifying the larval vertical distribution relative to the reversing layer, thus exposing larvae to different across-shelf current patterns. When larvae are concentrated in the surface (bottom) layer, an upwelling favorable wind generally causes larval offshore (onshore) movement and downwelling favorable wind causes onshore (offshore) transport.

Larval vertical swimming behavior, as defined in the model, is mainly dependent on water temperature and larval size (Zhang et al., 2015) . Larvae tend to swim in the vertical to get close to their most suitable temperature range of $\sim 20-21^{\circ} \mathrm{C}$, but a countervailing sinking rate also increases 
with increased larval size. These two factors, however, are not completely independent as the water temperature experienced by larvae also determines growth rate and hence larval size. Here the main focus is on the effects of water temperature. The water temperature at the reversing depth where the across-shelf current reverses direction is assumed to be the lower limit of surface water temperature, and is used as the criterion for defining surface layer temperature. The regression of larval vertical position with respect to the reversing depth (i.e. larval depth minus the reversing depth) against water temperature at the reversing depth shows an inverse linear relationship for all larvae at all times within the MAB shelf (Fig. 8). This mean trend indicates that as the surface water temperature increases, larvae tend to get deeper in the water column relative to the reversing depth, and vice versa. The high variability of larval trajectories associated with intrinsic fine-scale processes (e.g., vertical turbulent mixing, parameterized here by a random walk, as mentioned in section 3.1) ensures that larvae, even those released "close" together, will separate in time, first vertically then horizontally. This produces a statistical "envelope" to the regression line in Figure 8.

This regression provides a critical value of water temperature (Fig. 8), defined as the value corresponding to the zero depth difference in the regression, such that when the water temperature at the reversing depth is greater than the critical value, larvae will concentrate below the reversing depth in the bottom layer, and vice versa. It is worth noting however that in addition, water temperature influences vertical larval position indirectly through its effect on larval growth and hence size. Therefore, the relationship between larval vertical distribution and water temperature is not purely linear, and the critical value obtained here from the linear regression analysis is only a statistical estimate, not a deterministic forcing factor. 


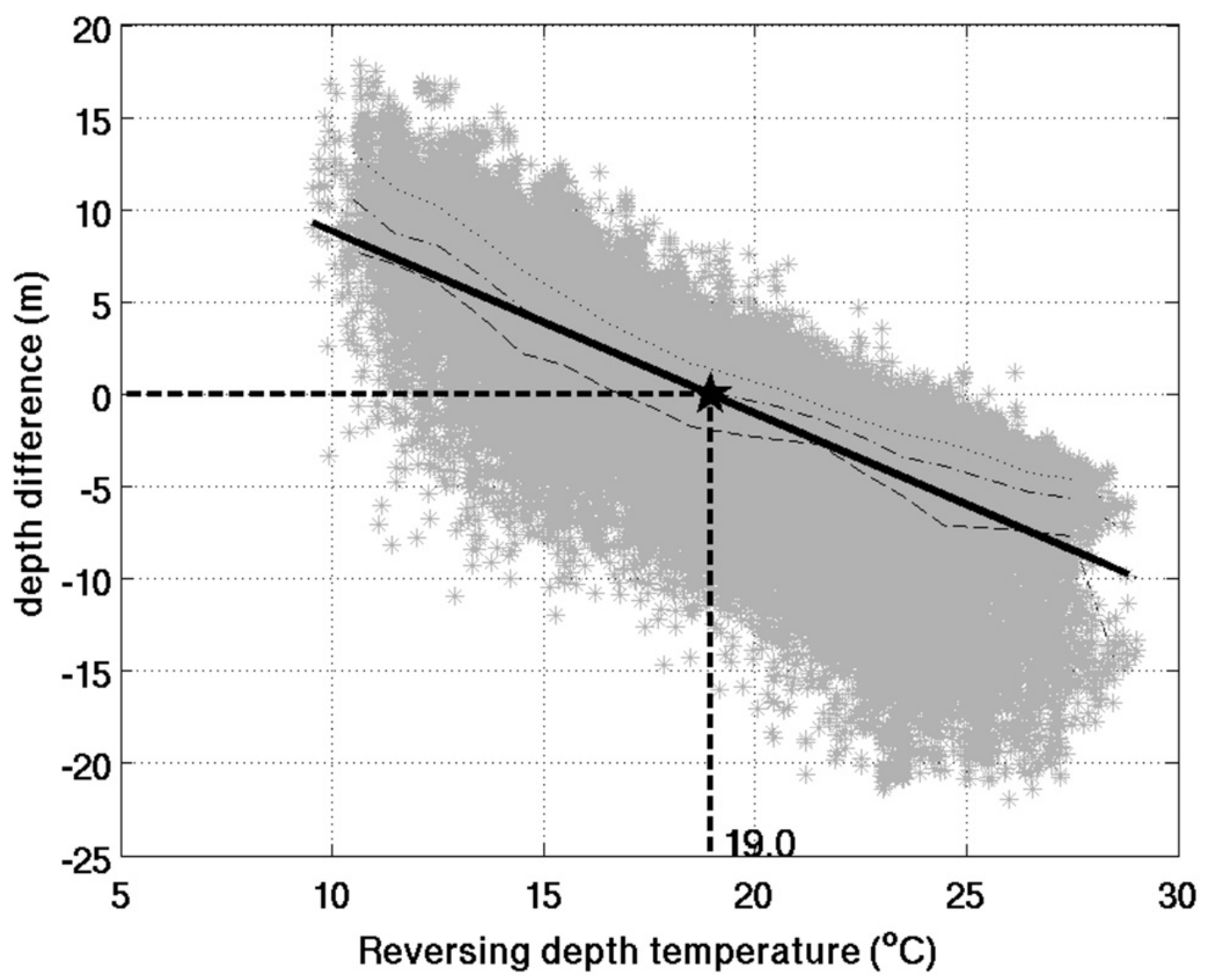

Figure 8. Depth difference (larval depth minus the across-shelf current reversing depth, in m, y-axis) versus water temperature at the reversing depth $\left({ }^{\circ} \mathrm{C}\right.$, x-axis) for larvae within $\mathrm{MAB}\left(\mathrm{NJ}^{*}, \mathrm{DMV}^{*}\right.$, and $\left.\mathrm{SVA}^{*}\right)$. The heavy black line indicates the linear regression between these two variables ( $\mathrm{p}$-value $<0.001$ ). Positive depth differences indicate that the larvae are above the reversing depth, and negative values indicate larvae below. The black star shows the water temperature at which larvae are at reversing depth (critical water temperature). Figure includes larvae of all size classes. Dashed and dotted lines show the $25^{\text {th }}$ (bottom), $50^{\text {th }}$ (middle), and $75^{\text {th }}$ (top) percentiles of larval depth by temperature.

Observational studies of the vertical distribution of surfclam larvae and their across-shelf transport show contrasting patterns between the NJ* (Ma, 2005; Ma and Grassle, 2004; Ma et al., 2006) and SVA* shelf (Garland and Zimmer, 2002; Garland et al., 2002; Shanks et al., 2002; Shanks et al., 2003). Off $\mathrm{NJ}^{*}$, along a cross-shelf transect in July of 1997 and 1998, surfclam larvae were concentrated above the thermocline and followed surface layer horizontal water movement; whereas off SVA* in August of 1994 larvae were concentrated below the thermocline and followed the bottom layer horizontal water movement. Model results for 2006 produce the same contrasting patterns as those observed for larvae on both the $\mathrm{NJ}^{*}$ and SVA* shelves in the same months $($ Fig. 5,6$)$. 
One possible mechanism causing the differences in vertical distribution and across-shelf movement is differing water temperature at the reversing depth in the two regions. Model results show that the mean water temperature at the reversing depth on the $\mathrm{NJ}^{*}$ shelf in July of 2006 was around $17^{\circ} \mathrm{C}$, a value lower than the critical value of water temperature of $19^{\circ} \mathrm{C}$ (Fig. 8). Accordingly, larvae were found close to or above the reversing depth and observed to follow the surface layer across-shelf water movement. Likewise, simulations off SVA* in August of 2006 had mean water temperature at the reversing depth of $22^{\circ} \mathrm{C}$, higher than the critical value, and as a result larvae were mostly found below the reversing depth and followed the bottom layer across-shelf flow. In the observational studies, the thermocline temperature on the $\mathrm{NJ}^{*}$ shelf in mid July of 1998 was around $16^{\circ} \mathrm{C}$ (Ma et al., 2006), lower than the critical value, and larvae congregated in the surface layer; whereas the temperature of the thermocline off SVA* in late August of 1994 was around $18.5 \sim 22^{\circ} \mathrm{C}$ (Austin, 1999; Garland et al., 2002; Shanks et al., 2002; Shanks et al., 2003), close to or higher than the critical value, and larvae were observed to congregate in the bottom layer. Thus, the cause of the difference in the vertical distributions of surfclam larvae and their across-shelf transport pattern between larvae off $\mathrm{NJ}^{*}$ and $\mathrm{SVA}^{*}$ is likely due to differences in water temperature at the reversing depth.

Analysis of model results show that $61 \%, 69 \%$ and $77 \%$ of surfclam larvae released off $\mathrm{NJ}$, DMV, and SVA shelves respectively are below the reversing depth when the water column is stratified. In the summer months (June-August) when upwelling favorable wind generally dominates, larvae off the $\mathrm{NJ}^{*}$, $\mathrm{DMV}^{*}$ and $\mathrm{SVA}^{*}$ shelves mostly experience onshore transport. This also explains the previous finding that, for larvae released from NJ, which are mainly transported along the $\mathrm{NJ}^{*}$ and $\mathrm{DMV}^{*}$ shelves, and larvae released from DMV, which are mainly transported along the $\mathrm{DMV}^{*}$ and $\mathrm{SVA}^{*}$ shelves, total larval transport is in the onshore direction (Fig. 3d-2).

\section{Conclusion}

In this study, a physical circulation model covering the Middle Atlantic Bight, Georges Bank and Gulf of Maine was coupled to a surfclam larval model to investigate variations in larval transport and settlement in 2006, and also to investigate the primary mechanisms underlying these

variations. Model results show that the highest larval settlement rate occurs when larvae are 
released during July to early October, corresponding to the higher average temperatures experienced by the larvae.

Larval along-shore transport exhibits a mean downstream pattern following the mean coastal current from the northeast to the southwest, with the maximum southwestward transport occurring for the August releases. Most high-frequency (periods of 2 10 days) variations in alongshore larval transport are associated with changes in the along-shore surface wind stress, whereas the seasonal variation seems to be mainly driven by changes in the across-shelf density gradient. A forward phase shift in the seasonal signal is observed to occur from inshore to offshore larvae, with the offshore larvae experiencing maximum southwestward along-shore drift later by around 20 days than the inshore larvae. This result indicates the importance of larval across-shelf movement in affecting the overall connectivity pattern within the surfclam stock.

In the across-shelf direction, larvae released from the New Jersey, Delmarva and South Virginia shelves experience mostly onshore transport during the summer months when upwelling favorable wind dominates. This is explained by two mutually dependent factors, water temperature and larval size, that affect the larval vertical distribution through their influence on larval vertical swimming and sinking behaviors. Statistical estimates based on all larvae released within the Middle Atlantic Bight shelf during the stratified season show a critical value of water temperature at $19.0^{\circ} \mathrm{C}$, such that when the water temperature at the thermocline is above this critical value, surfclam larvae tend to escape the warm surface layer to concentrate below the thermocline and follow the bottom layer across-shelf movement, and vice versa.

This critical water temperature theory also successfully explains previously observed differences in larval vertical distribution and across-shelf movement patterns between the NJ shelf in July of 1997 and 1998, and the SVA shelf in August of 1994. This confirms the importance of water temperature not only in determining surfclam larval settlement rate but also in affecting their vertical distribution, across-shelf transport, and along-shore transport. These results collectively provide an important insight into the general mechanism of how physical environmental factors interact with biological behavior to influence larval transport, population connectivity, and 
population dynamics, while providing a mechanism by which climate variability and change may significantly impact benthic species and coastal ecosystems.

\section{Acknowledgement}

The authors acknowledge generous insight and discussion contributed to this work by R. Mann and colleagues at the National Marine Fisheries Service, D. Hennen, L. Jacobsen and T. Chute. Fred Castruccio provided initial parameterizations on which this model domain was based, and J. Klinck provided assistance with larval model components. The authors also thank H. Ma at NOAA PIFSC for the helpful discussion and input. This study was primarily supported by the National Science Foundation project, "Collaborative Research: Climate Change and Responses in a Coupled Marine System" awarded under the Coupled Natural and Human Systems program (Award \#GEO0909484). D.M. was partially supported by USDA National Institute of Food and Agriculture Hatch project accession number 1002345 through the New Jersey Agricultural Experiment Station, Hatch project NJ32115. The authors thank the Rutgers Institute of Marine and Coastal Sciences Ocean Modeling Group for access to the ROMS model source code and providing the computational resources required for this study. Contributions of anonymous reviewers greatly improved this manuscript.

\section{Reference}

Aikman, F., Posmentier, E.S., 1985. Stratification and shelf-slope interaction in the Middle Atlantic Bight - a numerical study. Journal of Geophysical Research-Oceans 90, 4895-4905.

Austin, J.A., 1999. The role of the alongshore wind stress in the heat budget of the North Carolina inner shelf. Journal of Geophysical Research-Oceans 104, 18187-18203. DOI: 10.1029/1998JC900122

Backus, R.H., 1987. Geology, in: Backus, R.H. (Ed.), Georges Bank. MIT Press, Cambridge, MA, pp. $22-$ 24. 
Beardsley, R.C., Boicourt, W.C., 1981. On estuarine and continental - shelf circulation in the Middle Atlantic Bight, in: Warren, B.A., Wunsch, C. (Eds.), Evolution of physical oceanography: scientific surveys in honor of Henry Stommel. MIT Press, Cambridge, Mass, pp. 198-235.

Bleck, R., 2002. An Oceanic general circulation model framed in hybrid isopycnic-Cartesian coordinates. Ocean Modelling 4, 55-88. doi:10.1016/S1463-5003(01)00012-9

Bos, O.G., Hendriks, I.E., Strasser, M., Dolmer, P., Kamermans, P., 2006. Estimation of food limitation of bivalve larvae in coastal waters of north-western Europe. Journal of Sea Research 55, 191-206. doi:10.1016/j.seares.2005.10.006

Cargnelli, L.M., Griesbach, S.J., Packer, D.B., Weissberger, E., 1999. Atlantic surfclam, Spisula solidissima, life history and habitat characteristics. Essential fish habitat source document. NOAA Technical Memorandum NMFS-NE-142 Northeast Fisheries Science Center, Woods Hole, Massachusetts.

Castelao, R., Glenn, S., Schofield, O., Chant, R., Wilkin, J., Kohut, J., 2008. Seasonal evolution of hydrographic fields in the central Middle Atlantic Bight from glider observations. Geophysical Research Letters 35, L03617, doi:10.1029/2007GL032335

Condie, S.A., Waring, J., Mansbridge, J.V., Cahill, M.L., 2005. Marine connectivity patterns around the Australian continent. Environmental Modelling \& Software 20, 1149-1157. doi:10.1016/j.envsoft.2004.07.005

Dekshenieks, M.M., Hofmann, E.E., Klinck, J.M., Powell, E.N., 1996. Modeling the vertical distribution of oyster larvae in response to environmental conditions. Marine Ecology Progress Series 136, 97 110.

Dzwonkowski, B., Kohut, J.T., Yan, X.H., 2009. Seasonal differences in wind-driven across-shelf forcing and response relationships in the shelf surface layer of the central Mid-Atlantic Bight. Journal of Geophysical Research-Oceans 114, C08018, doi:10.1029/2008JC004888 
Edwards, K.P., Hare, J.A., Werner, F.E., Seim, H., 2007. Using 2-dimensional dispersal kernels to identify the dominant influences on larval dispersal on continental shelves. Marine Ecology Progress Series 352, 77-87. doi:10.3354/meps07169

Fay, C.W., Neves, R.J., Pardue, G.B., 1983. Life histories and environmental requirements of coastal fishes and invertebrates (Mid-Atlantic). Surfclam. Virginia Polytechnic Institute and State University, Blacksburg, USA.

Fong, D.A., Geyer, W.R., 2002. The alongshore transport of freshwater in a surface-trapped river plume. Journal of Physical Oceanography 32, 957-972.

Garland, E.D., Zimmer, C.A., 2002. Hourly variations in planktonic larval concentrations on the inner shelf: Emerging patterns and processes. Journal of Marine Research 60, 311-325. DOI: http://dx.doi.org/10.1357/00222400260497507

Garland, E.D., Zimmer, C.A., Lentz, S.J., 2002. Larval distributions in inner-shelf waters: The roles of wind-driven cross-shelf currents and diel vertical migrations. Limnology and Oceanography 47, 803-817. DOI: $10.4319 /$ lo.2002.47.3.0803

Gawarkiewicz, G., Monismith, S., Largier, J., 2007. Observing larval transport processes affecting population connectivity progress and challenges. Oceanography 20, 40-53. http://dx.doi.org/10.5670/oceanog.2007.28

Gireesh, R., Gopinathan, C.P., 2008. Effects of microalgal diets on larval growth and survival of Paphia malabarica chemnitz. Aquaculture Research 39, 552-556. doi: 10.1111/j.1365-2109.2008.01913.x

GLOBEC, 1991. Global Ocean Ecosystems Dynamics, Initial Science Plan, Washington, D.C, p. 93.

Gong, D., Kohut, J.T., Glenn, S.M., 2010. Seasonal climatology of wind-driven circulation on the New Jersey Shelf. Journal of Geophysical Research-Oceans 115. C04006, doi:10.1029/2009JC005520 
Hare, J.A., Churchill, J.H., Cowen, R.K., Berger, T.J., Cornillon, P.C., Dragos, P., Glenn, S.M., Govoni, J.J., Lee, T.N., 2002. Routes and rates of larval fish transport from the southeast to the northeast United States continental shelf. Limnology and Oceanography 47, 1774-1789. DOI: 10.4319/10.2002.47.6.1774

Hare, J.A., Cowen, R.K., 1996. Transport mechanisms of larval and pelagic juvenile bluefish (Pomatomus saltatrix) from South Atlantic Bight spawning grounds to Middle Atlantic Bight nursery habitats. Limnology and Oceanography 41, 1264-1280. DOI: 10.4319/lo.1996.41.6.1264

Harris, C.K., Butman, B., Traykovski, P., 2003. Winter-time circulation and sediment transport in the Hudson Shelf Valley. Continental Shelf Research 23, 801-820. DOI: 10.1016/S02784343(03)00025-6

Hickey, B.M., 1979. The California Current system-hypotheses and facts. Progress in Oceanography 8, 191-279.

Hill, A.E., 1991. Vertical migration in tidal currents. Marine Ecology Progress Series 75, 39-54.

Houghton, R.W., Schlitz, R., Beardsley, R.C., Butman, B., Chamberlin, J.L., 1982. The Middle Atlantic Bight cold pool: Evolution of the temperature structure during summer 1979. Journal of Physical Oceanography 12, 1019-1029.

Jones, D.S., 1981. Reproductive cycles of the Atlantic surf clam Spisula solidissima, and the ocean quahog Arctica islandica off New Jersey. Journal of Shellfish Research 1, 23-32.

Kim, Y., Powell, E.N., 2004. Surfclam histopathology survey along the Delmarva mortality line. Journal of Shellfish Research 23, 429-441.

Kohut, J.T., Glenn, S.M., Chant, R.J., 2004. Seasonal current variability on the New Jersey inner shelf. Journal of Geophysical Research-Oceans 109, C07S07, doi:10.1029/2003JC001963 
Leaman, K.D., Johns, E., Rossby, T., 1989. The average distribution of volume transport and potential vorticity with temperature at three sections across the Gulf Stream. Journal of Physical Oceanography $\quad 19, \quad 36-51$ doi: http://dx.doi.org/10.1175/15200485(1989)019<0036:TADOVT>2.0.CO;2

Lentz, S.J., 2001. The influence of stratification on the wind-driven cross-shelf circulation over the North Carolina shelf. Journal of Physical Oceanography 31, 2749-2760.

Lentz, S.J., 2008a. Observations and a model of the mean circulation over the Middle Atlantic Bight continental shelf. Journal of Physical Oceanography 38, 1203-1221. http://dx.doi.org/10.1175/2007JPO3768.1

Lentz, S.J., 2008b. Seasonal variations in the circulation over the Middle Atlantic Bight continental shelf. Journal of Physical Oceanography 38, 1486-1500. http://dx.doi.org/10.1175/2007JPO3767.1

Lough, R.G., Buckley, L.J., Werner, F.E., Quinlan, J.A., Edwards, K.P., 2005. A general biophysical model of larval cod (Gadus morhua) growth applied to populations on Georges Bank. Fisheries Oceanography 14, 241-262. DOI: 10.1111/j.1365-2419.2005.00330.x

Ma, H.G., 2005. Spatial and temporal variation in surfclam (Spisula solidissima) larval supply and settlement on the New Jersey inner shelf during summer upwelling and downwelling. Estuarine Coastal and Shelf Science 62, 41-53. doi:10.1016/j.ecss.2004.08.005

Ma, H.G., Grassle, J.P., 2004. Invertebrate larval availability during summer upwelling and downwelling on the inner continental shelf off New Jersey. Journal of Marine Research 62, 837-865. DOI: $10.1357 / 0022240042880882$

Ma, H.G., Grassle, J.P., Chant, R.J., 2006. Vertical distribution of bivalve larvae along a cross-shelf transect during summer upwelling and downwelling. Marine Biology 149, 1123-1138. DOI: $10.1007 / \mathrm{s} 00227-006-0287-3$ 
Marra, J., Houghton, R.W., Garside, C., 1990. Phytoplankton growth at the shelf-sreak front in the Middle Atlantic Bight. Journal of Marine Research 48, 851-868.

McCay, B.J., Brandt, S., Creed, C.F., 2011. Human dimensions of climate change and fisheries in a coupled system: the Atlantic surfclam case. ICES Journal of Marine Science 68, 1354-1367. doi: 10.1093/icesjms/fsr044

Moran, A.L., Manahan, D.T., 2004. Physiological recovery from prolonged 'starvation' in larvae of the Pacific oyster Crassostrea gigas. Journal of Experimental Marine Biology and Ecology 306, 17 36.doi:10.1016/j.jembe.2003.12.021

Munk, P., Larsson, P.O., Danielsen, D., Moksness, E., 1995. Larval and small juvenile cod Gadus morhua concentrated in the highly productive areas of a shelf break front. Marine Ecology Progress Series 125, 21-30. doi:10.3354/meps 125021

Munroe, D.M., Klinck, J.M., Hofmann, E.E., Powell, E.N., 2012. The role of larval dispersal in metapopulation gene flow: Local population dynamics matter. Journal of Marine Research 70, 441-467. DOI: http://dx.doi.org/10.1357/002224012802851869

NEFSC, 2010. 49th Northeast Regional Stock Assessment Workshop (49th SAW) Assessment Report, Northeast Fisheries Science Center Reference Document. United States Department of Commerce, p. 383 .

Ólafsson, E.B., Peterson, C.H., Ambrose, W.G., 1994. Does recruitment limitation structure populations and communities of macro-invertebrates in marine soft sediments: the relative significance of presettlement and postsettlement processes. Oceanography and Marine Biology, Vol 32 32, 65-109.

Olson, R.R., Olson, M.H., 1989. Food limitation of planktotrophic marine invertebrate larvae - Does it control recruitment success. Annual Review of Ecology and Systematics 20, 225-247. 
Pfeiffer-Hoyt, A.S., McManus, M.A., 2005. Modeling the effects of environmental variability on Balanus glandula larval development. Journal of Plankton Research 27, 1211-1228. doi: 10.1093/plankt/fbi089

Pineda, J., Hare, J.A., Sponaugle, S., 2007. Larval transport and dispersal in the coastal ocean and consequences for population connectivity. Oceanography 20, 22-39. http://dx.doi.org/10.5670/oceanog.2007.27

Powell, E.N., Bochenek, E.A., Klinck, J.M., Hofmann, E.E., 2002. Influence of food quality and quantity on the growth and development of Crassostrea gigas larvae: a modeling approach. Aquaculture 210, 89-117. doi:10.1016/S0044-8486(01)00891-2

Przeslawski, R., Webb, A.R., 2009. Natural variation in larval size and developmental rate of the northern Quahog Mercenaria mercenaria and associated effects on larval and juvenile fitness. Journal of Shellfish Research 28, 505-510. doi: http://dx.doi.org/10.2983/035.028.0312

Ropes, J.W., 1968. Hermaphroditism in the surf clam, Spisula solidissima. Proceedings of the National Shellfisheries Association 58, 63-65.

Ropes, J.W., 1980. Biological and fisheries data on the Atlantic surf clam, Spisula solidissima. Northeast Fisheries Center, National Marine Fisheries Service, National Oceanic and Atmospheric Administration, Woods Hole, Massachusetts.

Rumrill, S.S., 1990. Natural mortality of marine invertebrate larvae. Ophelia 32, 163-198.

Shanks, A.L., Largier, J., Brink, L., Brubaker, J., Hooff, R., 2002. Observations on the distribution of meroplankton during a downwelling event and associated intrusion of the Chesapeake Bay estuarine plume. Journal of Plankton Research 24, 391-416.

Shanks, A.L., Largier, J., Brubaker, J., 2003. Observations on the distribution of meroplankton during an upwelling event. Journal of Plankton Research 25, 645-667. doi: 10.1093/plankt/25.6.645 
Shearman, R.K., Lentz, S.J., 2003. Dynamics of mean and subtidal flow on the New England shelf. Journal of Geophysical Research-Oceans 108, NO. C8, 3281, doi:10.1029/2002JC001417

Smith, W.G., Morse, W.W., 1985. Retention of larval haddock Melanogrammus aeglefinus in the Georges Bank Region, a gyre-influenced spawning area. Marine Ecology Progress Series 24, 1-13.

Swearer, S.E., Shima, J.S., Hellberg, M.E., Thorrold, S.R., Jones, G.P., Robertson, D.R., Morgan, S.G., Selkoe, K.A., Ruiz, G.M., Warner, R.R., 2002. Evidence of self-recruitment in demersal marine populations. Bulletin of Marine Science 70, 251-271.

Thorson, G., 1966. Some factors influencing the recruitment and establishment of marine benthic communities. Netherlands Journal of Sea Research 3, 267-293.

Ullman, D.S., Codiga, D.L., 2004. Seasonal variation of a coastal jet in the Long Island Sound outflow region based on HF radar and Doppler current observations. Journal of Geophysical ResearchOceans 109. C07S06, doi:10.1029/2002JC001660

Weinberg, J.R., Powell, E.N., Pickett, C., V.A, N.J., Jacobson, L.D., 2005. Results from the 2004 cooperative survey of Atlantic surfclams, Northeast Fishery Science Center Reference Documents, pp. 1-41.

Werner, F.E., Page, F.H., Lynch, D.R., Loder, J.W., Lough, R.G., Perry, R., Greenberg, D.A., Sinclair, M.M., 1993. Influences of mean advection and simple behavior on the distribution of cod and haddock early life stages on Georges Bank. Fisheries Oceanography 2, 43-64. DOI: 10.1111/j.1365-2419.1993.tb00120.x

Zhang, W.G.F., Wilkin, J.L., Chant, R.J., 2009. Modeling the pathways and mean dynamics of river plume dispersal in the New York Bight. Journal of Physical Oceanography 39, 1167-1183. doi: http://dx.doi.org/10.1175/2008JPO4082.1

Zhang, X., Haidvogel, D.B., Munroe, D., Powell, E.N., Klinck, J., Mann, R., Castruccio, F., 2015. Modeling larval connectivity of the Atlantic surfclams within the Middle Atlantic Bight: Model 
development, larval dispersal and metapopulation connectivity. Estuarine, Coastal and Shelf Science 153, 38-53. doi:10.1016/j.ecss.2014.11.033 

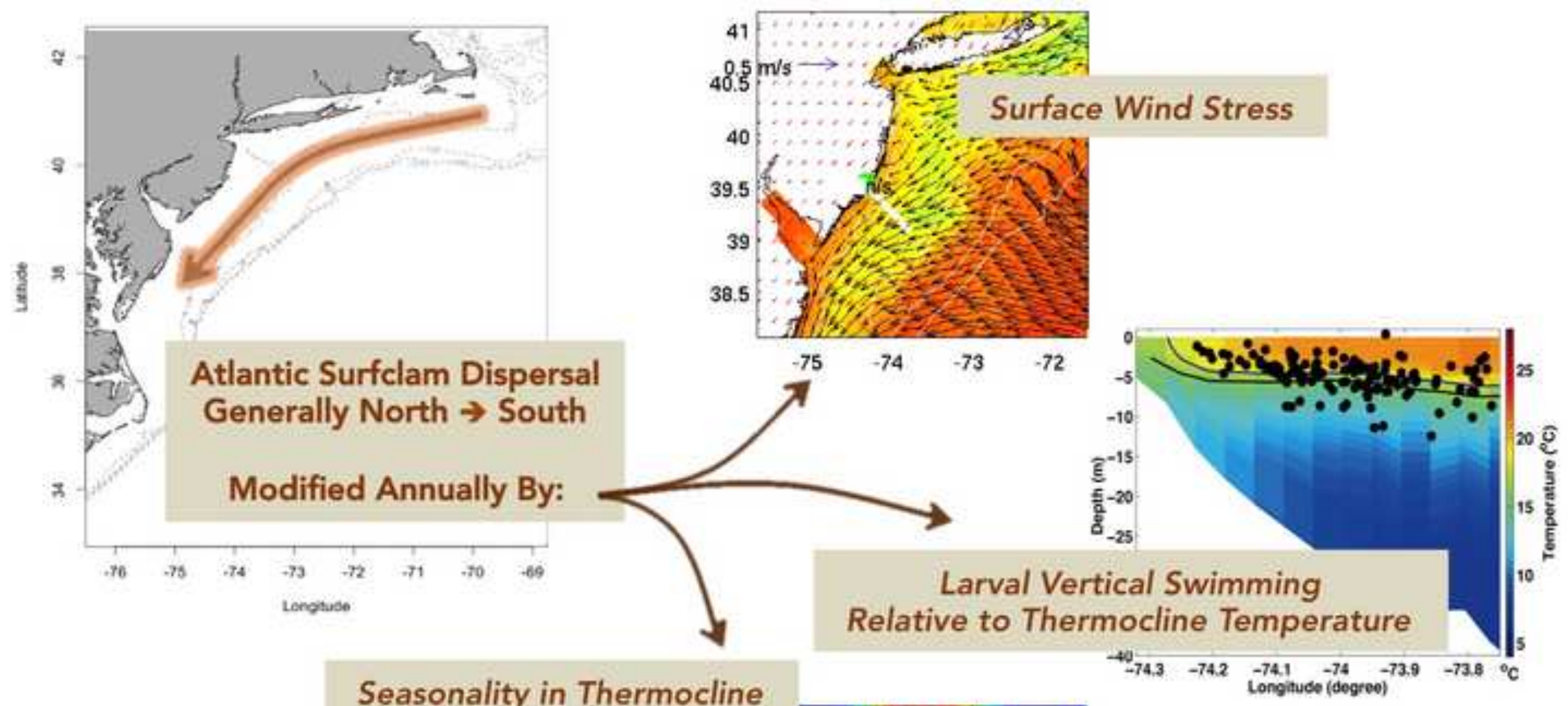

Seasonality in Thermocline

Set-Up and Breakdown

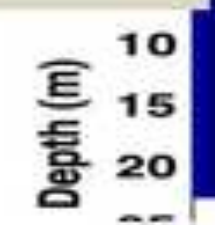

